\title{
The Impacts of an Outdoor Orientation Program on Participants' Self Evaluated Trait Emotional Intelligence
}

\author{
Coy James Belknap III \\ West Virginia University
}

Follow this and additional works at: https://researchrepository.wvu.edu/etd

\section{Recommended Citation}

Belknap, Coy James III, "The Impacts of an Outdoor Orientation Program on Participants' Self Evaluated Trait Emotional Intelligence" (2011). Graduate Theses, Dissertations, and Problem Reports. 4694. https://researchrepository.wvu.edu/etd/4694

This Thesis is protected by copyright and/or related rights. It has been brought to you by the The Research Repository @ WVU with permission from the rights-holder(s). You are free to use this Thesis in any way that is permitted by the copyright and related rights legislation that applies to your use. For other uses you must obtain permission from the rights-holder(s) directly, unless additional rights are indicated by a Creative Commons license in the record and/ or on the work itself. This Thesis has been accepted for inclusion in WVU Graduate Theses, Dissertations, and Problem Reports collection by an authorized administrator of The Research Repository @ WVU. For more information, please contact researchrepository@mail.wvu.edu. 


\title{
The Impacts of an Outdoor Orientation Program on Participants' Self Evaluated Trait Emotional Intelligence
}

Coy James Belknap III

\author{
Thesis Submitted to the \\ Davis College of Agriculture, Natural Resources, and Design \\ at West Virginia University \\ in partial fulfillment of the requirements \\ for the degree of \\ Master of Science \\ in \\ Recreation, Parks and Tourism Resources Management
}

\author{
Chad D. Pierskalla, Ph.D., Chair \\ David Smaldone, Ph.D. \\ Ted Price, Ph.D. \\ Greg Corio, M.S. \\ Nathan Harlan, M.A.
}

Division of Forestry and Natural Resources

Recreation, Parks \& Tourism Resources

Morgantown, West Virginia

2011

Keywords: Emotional Intelligence; Outdoor Orientation; First Year Experience; Experiential Education; Trait Emotional Intelligence 


\section{Abstract \\ The Impacts of an Outdoor Orientation Program on Participants Self Evaluated Trait Emotional Intelligence.}

\section{Coy James Belknap III}

In taking the applications of both emotional intelligence and outdoor orientation programs, this present study employed a quasi-experimental approach to study the change associated with first year students transitioning into a collegiate setting. In conveying multiple levels of University 101 curriculum in a dynamic outdoor setting, Adventure West Virginia (AWV) was utilized in order to gauge the elicited impacts associated with outdoor orientation upon students' emotional intelligence, most specifically trait emotional intelligence (TEI). Four individual programs (Explore, Habitat, Wilderness and Odyssey) were studied, with elements of each trip and student characteristics taken into account during analysis. Overall, this study sought to identify the elements, if any, which helped in the raising of TEI and the factors that consist of this specialized construct.

Measurements of differences between pre-test and post-test values of the Trait Emotional Intelligence Questionnaire-Short Form (TEIQ-SF) were made. T-tests along with Chisquare analyses and ANOVA tables helped develop a framework for which significance was sought, as both evidence supporting the development of TEI and a student typology was desired. In all, this sought to gauge the elicited impacts of TEl all while developing a student profile, depicting the type of student participating in AWV.

Results show significant increases in all TEl factors including Global TEI. These results were significant and support the notion that TEI can be raised, especially in relation to outdoor based collegiate orientation programs. The student typology assisted in breaking down and stratifying the TEl scores, with low, medium and high scores being accounted for. This diversification of students allowed for motivations to be implied, developing a student typology that incorporates TEI, motivations and student demographic data. Isolated analysis allowed for the elaboration of scores to be further simplified, with the stratified TEl scores paired along specific trip types within AWV. In all, Wilderness was the only program found to have adverse impacts upon TEI for AWV, actually lowering the construct within many of its factors. 


\section{Dedication}

To my family, friends and colleagues who have been a source for unconditional support and motivation. 


\section{Acknowledgement}

A special thanks goes to all who have assisted along the way. With your understanding, support and encouragement, this work was able to be completed. Thank you to all who assisted during my times of need, offering assistance when necessary. Thank you to the Mountaineer Adventure Program for paving the way necessary for the research done. Above all, thank you to my family and fiancé. Your understanding and support drove and supplied the strength needed in order to complete this work.

\section{THANK YOU}




\section{Table of Contents}

\section{Chapter}

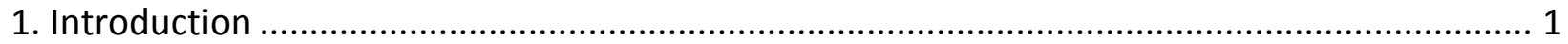

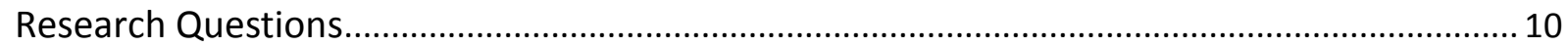

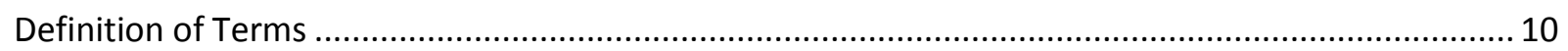

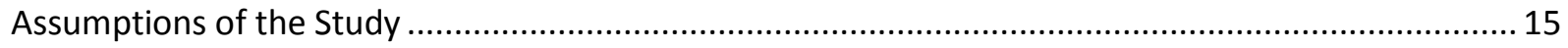

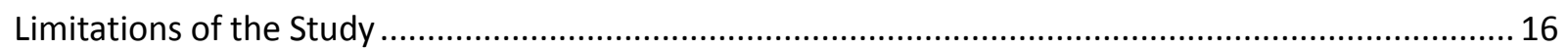

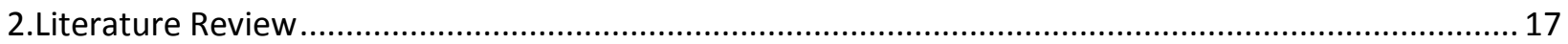

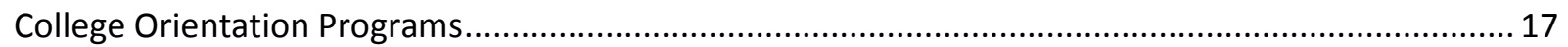

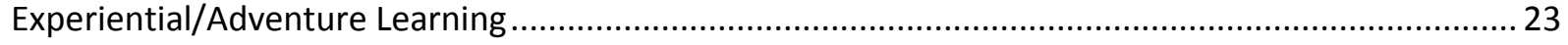

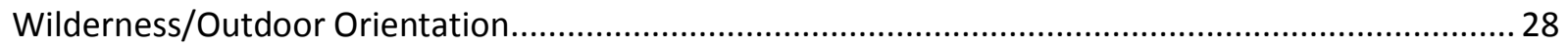

Emotional Intelligence/Trait Emotional Intelligence …................................................................ 32

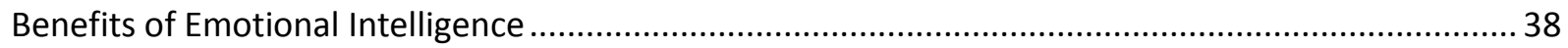

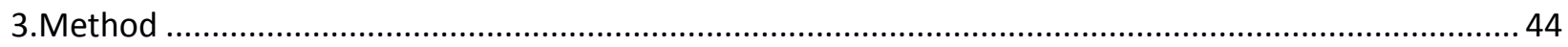

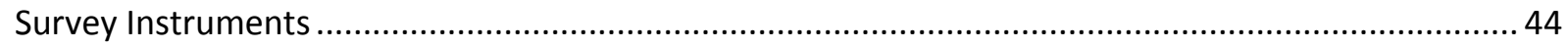

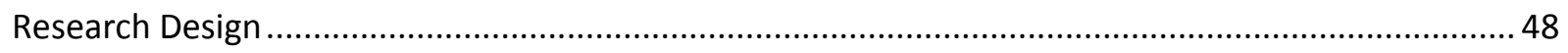

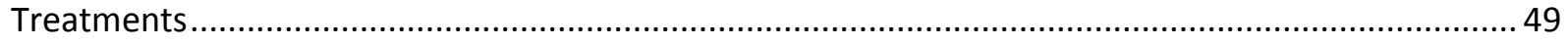

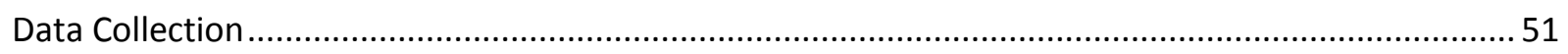

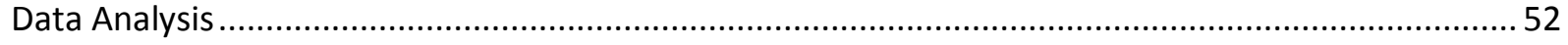

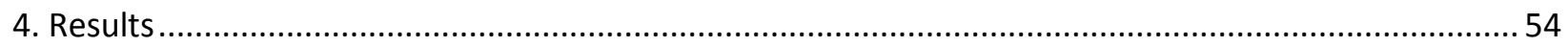

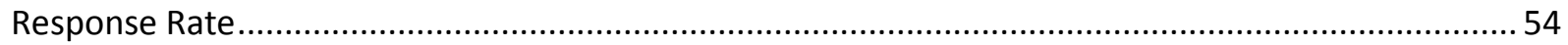

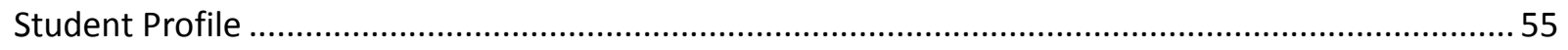

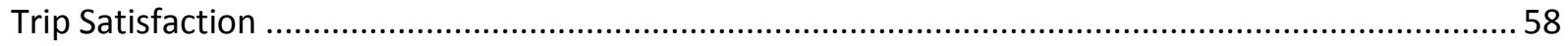

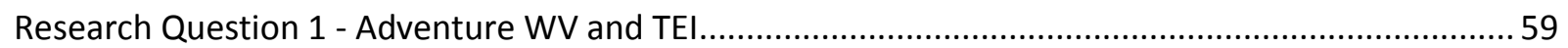

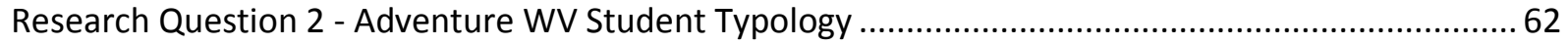

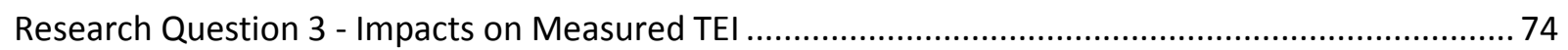

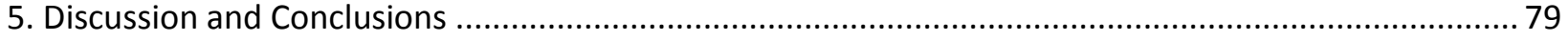

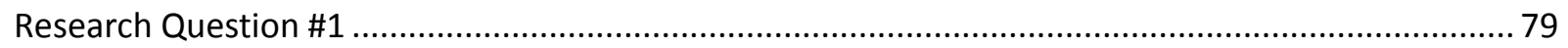

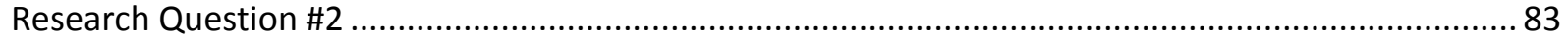

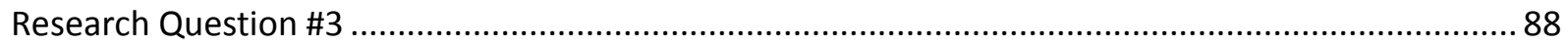

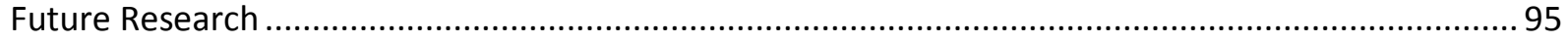

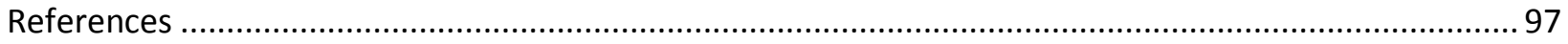

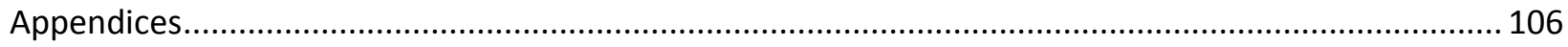




\section{List of Figures}

Figure 1: Kolb's Four Stage Experiential Learning Cycle .................................................... 26

Figure 2: The mediating role of TEI in scholastic success ..................................................... 41

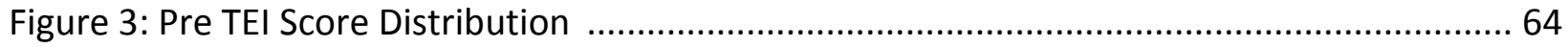




\section{List of Tables}

Table 1: The Factorial and Subscale Sampling Domain for Trait El ..................................................37

Table 2: Selected REP Domains, Scales and Core Statements ......................................................45

Table 3: Explanation of Treatments within AWV .......................................................................50

Table 4: Response Rate for Survey Instrument ...........................................................................55

Table 5: Student Profile Characteristics .......................................................................................57

Table 6: Trip Satisfaction and Preparation for College .................................................................58

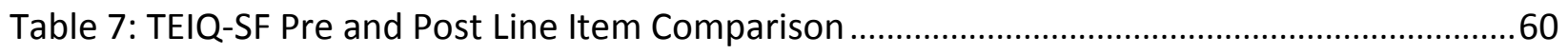

Table 8: TEIQ-SF Pre and Post Factor Item Comparison ...............................................................61

Table 9: TEIQ-SF Global TEI Pre and Post Comparison ...............................................................61

Table 10: Factor and Factor Loadings for Motivational Items .......................................................65

Table 11: TEI Segments and Motivational Domains ANOVA ........................................................68

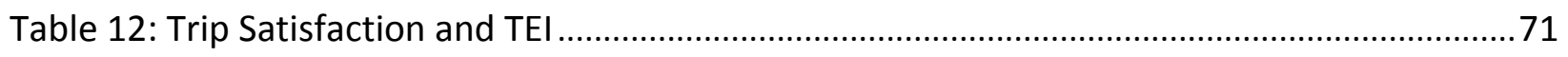

Table 13: TEl Segments and TEI Factors ANOVA …..................................................................... 72

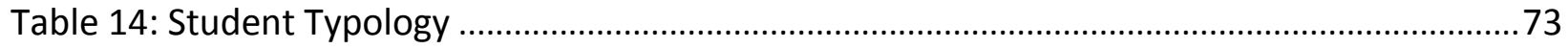

Table 15: ANOVA of TEI Factor and Global TEI MG scores for Four AWV Trips .............................75

Table 16: ANOVA of TEI Factor and Global TEI MG scores for AWV Trips and Low Segment .......77

Table 17: ANOVA of TEI Factor and Global TEI MG scores for AWV Trips and High Segment ......78 


\section{Introduction}

"We're being judged by a new yardstick: not just by how smart we are, or by our training and expertise, but also by how well we handle ourselves and each other" (Goleman, 1998). This statement, although not applied to any specific population, provides intuitive insight to the revolution that is weighing down on how we predict success. Instead of using our Intellectual Quotient (IQ), this new measure focuses primarily on a different set of skills and traits, such as initiative, empathy, adaptability and persuasiveness (Goleman, 1998). Research has shown these qualities help lay the basic groundwork for star performers and demonstrates that the human qualities listed above help make up the largest portion for excellence at work (Goleman, 1998). Academic prowess, although important, can be considered as only part of the equation and not nearly sufficient (Zee, Thijs \& Schakel, 2002; Abraham, 2006; Parker, Saklofske, Wood \& Collin, 2009; Ewert, 1977). This relatively new construct concerning our ability to become successful refers to the skills needed to help individuals deal with the stresses associated with life. Solving conflicts, collaborating with others and adjusting to new environments that differ culturally and in setting are all associated with these traits, as their application is not singularly defined (Zee et al., 2002). Although applicable to every person in any situation, this new construct bears special importance to one special sub-group, collegiate freshman. By experiencing a multitude of changes over a relative short amount of time, the development and understanding of trait emotional intelligence (TEI) for any collegiate freshmen can be considered a true high priority.

According to Liptak (2005), college students, more than ever, need a wider array of skills and abilities in order to become successful employees and citizens. Research (e.g., 
Goleman, 1998; LaPlante, 1991; Shivpuri\& Kim, 2004; Ewert, 1977) has shown that many students find that, once they have graduated college, their preparation in dealing with the facets associated with their personal and working lives have been ill prepared (Liptak, 2005). These statements are echoed by Chicerking, Dalton and Stamm (2006), as cited in Bobilya, Akey and Mitchell Jr. (2009), in that higher education has encouraged the development of "fragmented" lives, as the development of values, emotional maturity, moral development, spirituality and self-understanding have gone undeveloped. Simply having training in the hard skills associated with any situation( i.e. the skills needed to actually perform the physical aspects of any job) have come under scrutiny, as a completely new paradigm has been suggested in order to find success. This paradigm is coupled with the fact that emotional and social competencies are beginning to receive merit as predictors to academic success and retention (Parker et al., 2009). These findings have driven the belief that an alternative approach is needed to help students become better prepared as they participate in the daily functions within and out of college, especially within their preparation for professional life (Abraham, 2006).

One relatively new alternative in helping students prepare for colligate and professional experiences is the development of their emotional intelligence (EI). Goleman (1995) described El as a set of valuable skills, abilities and competencies that differ in nature to that of IQ. Traditionally, IQ has been viewed as an innate ability that is rather static in nature, whereas EI has the ability to be developed and expanded by anyone (Goleman, 1995). The skills associated with El are that of motivating oneself, being persistent in facing obstacles and achieving goals, having the ability to motivate one's self, empathize with others, controlling the fluctuations 
between moods, controlling the impulses or delaying gratification, thinking rationally and finallyhoping (Goleman, 1995). Mayer, Salovey and Caruso (2000), also define El as "the ability to perceive and express emotion, assimilate emotion in thought, understand and reason with emotion and regulate emotion in the self and others."

As indicated above, however, this relatively new construct has seen a great deal of development, as multiple definitions and operalizations of the term have been developed. Instead of being contradictory of each other, however, these definitions have been rather complimentary and have built upon the term so it incorporates an assortment of items and terms (Ciarrhochi, Chan \&Caputi, 2000). With historical roots in Thorndike's (1920) social intelligence and Gardner's (1983) theory of multiple intelligences (where he differentiates between interpersonal and intrapersonal intelligence), the construct of El has been expanded to incorporate a variety of fields in a variety of different research disciplines. One development, however, has seen the differentiation between two elements within El, trait and cognitive, with both representing the two different realms that are associated with the new construct. Trait EI (also known as emotional self-efficacy) and cognitive El represent the two constructs that exist in terms of measuring one's El ability (Petrides and Furnham, 2001). The latter represents the dispositions held by any person concerning their self-perceived abilities and is measured through self-reporting, whereas the former is concerned with the actual abilities held within any given individual and is only measured through maximum performance tests (Petrides and Furnham, 2001). Trait El has been operationalized by being placed within personality frameworks, most notably the Big Five Framework, and uses the term "trait" in order to differentiate itself from cognitive abilities, which is exclusively associated with cognitive El. This 
construct also consists of four factors (Well-Being, Self-Control, Emotionality, Sociability) that add together to comprise a global trait El score (Petrides \& Furnham, 2001). Through surveys that measure the dispositions comprising the affective aspects of personality (see Petride \&Furnham, 2001), trait El has been shown to have the ability to be a successful predictor of success for any individual in a variety of environments, especially collegiate students.

Although not necessarily developed to address the above traits directly, many higher education institutions have implemented orientation programs to help smooth the transition process into college for first time students (Bell, 2006). According to Gass (2003), “Orientation programs have long been a key element for creating positive transitions for students into college and university settings" (p. 34). These transitions are important due to the fact that movement from high school to college can be a difficult transition for many incoming freshmen. This transition usually incorporates students leaving the relative comfort of home to assume a new role in a completely new environment (Pascarella, Terenzini \& Wolfle, 1986). Culture shock may be a result of this transition, as significant social and psychological relearning will be required as students face encounters with new ideas, teachers, friends, beliefs, freedoms, opportunities all coupled with new academic, personal and social demands (Pascarella\&Terenzini, 1991). College orientation programs fundamentally assist students with these facets, as they try and acquaint students with the administrative regulations and expected behaviors that are expected of the institution, introduce them to the represented student organizations on campus, introduce them to the available student resources, help them create an academic plan and present opportunities to meet the faculty and staff of the represented institution (Jamelske, 2009; Pascarella et al., 1986). 
Orientation programs have a historical foundation. Their use in assisting students has been dated to more than a century ago. Dating back to 1880 s, when both Lee University and Boston University conducted the first orientation programs, colleges have been interested in developing programs that help with the adjustments needed for first year students (Gass, 1986; History of the First Year Seminar, 2002). Results have shown that the early weeks of transition at a university can be critical to the long-term adjustments a student will make while at a university (Bell, 2006; Baker \&Siryk, 1984; Fox, Zakely, Morris \& Jundt, 1993). Pre-semester (before the start of college) along with extended orientation programs (lasting throughout the duration of the semester) have been installed throughout the country, giving students an opportunity to ease into this transitional phase (Bell, 2006). Benefits associated with student development have been recorded as higher grade point averages (Bell, 2006; Barefoot, Warnock, Dickinson, Richardson \& Roberts, 1998; Porter \& Swing, 2006; Jamelske, 2009), higher persistence levels in staying for a degree (Bell, 2006; Barefoot et al., 1998; Hausmann, Schofield \&Woods, 2007), lower likelihood to be placed on academic probation (Porter \& Swing, 2006; Grout, 2009), higher likelihood of being involved on campus (Porter \& Swing, 2006;Jamelske, 2009; Grout, 2009), greater interaction with faculty (Porter \& Swing, 2006; Grout, 2009) and shorter time needed to complete a degree (Barefoot et al., 1998), and those benefits have been found in contrast to students who have not participated in orientation programs. The majority of these orientation programs also focus on outlining the expectations set by the university's administration on how students will be integrated into the institution's culture (Bell, 2006).

Usually offered as an alternative or addition to traditional orientation programs, wilderness orientation programs have been offered in recent years to help students with this 
transition process. College outdoor orientation programs date back to 1935 when Dartmouth began leading precollege trips for their first-year students (Bell, Holmes, Vigneault, \&Williams, 2007;Gass, 1986). Although the goals of the various programs may differ from traditional orientation programs, the purpose usually coveys the same message as wilderness programs-to assist with the transition of first year students while reducing attrition and facilitating student development (Gass, 1986.) These programs have now expanded to more than 200 universities (Bell, 2008, Berman \& Berman, 1996). These programs involve a range of activities (e.g., backpacking, canoeing, climbing, ropes course), number of participants (4 to 1,080 people), length of program (1 to 24 days), and cost to participate (\$0 to \$212 per day) (Bell, 2008, Berman \& Berman, 1996).

Evidence supporting the use of outdoor programs has also surfaced. Although research on the topic is limited, the benefits of participating in a wilderness orientation program have been shown to imitate, and even outperform, many of the traditional orientation programs. As an example, Gass (1986) conducted a longitudinal study gauging the impacts a wilderness orientation program had on multiple variables in relation to first year students. First year students had the opportunity to participate in a wilderness orientation program, a freshmen camp or a control group that participated in no orientation program at all. The results of the study showed that students who participated in the wilderness orientation program experienced greater prolonged gains in the multiple variables measured throughout the study (Gass, 1986). After two semesters, the wilderness participants experienced higher retention rates, higher GPA scores and higher results on student development behaviors (developing 
autonomy, developing interpersonal relationships, interdependence, tolerance and developing appropriate relationships with the opposite sex) (Gass, 1986).

Bell (2006) focused on the social aspects related to students in transition, as he primarily focused on comparing a wilderness based orientation program to other programs coupled in the study. Through his work, Bell (2006) found that the wilderness based orientation program fared better in the social preparation of students in comparison to the non-participatory individuals. Bell (2006) used the Social Provision Scale (SPS) to gauge the effects of a wilderness orientation program on students in six distinct areas (attachment, social integration, competence, reliable alliance, guidance and opportunity for nurturance) at two different schools. All first and second year students were invited to participate in the event, as the wilderness orientation programs at both universities significantly impacted the categories associated with the SPS (Bell, 2006). Although other orientation programs were considered (pre-season athletics and a community action projects), the wilderness orientation program was the only program found to have significantly impacted the students in all the areas of social integration (Bell, 2006).

Although not every study has communicated the benefits shown above, the impact associated with wilderness orientation programming is evident in the literature. Nevertheless, literature associated with wilderness programs and their ability to raise trait emotional intelligence is severely limited. Having literature depicting the benefits associated with wilderness orientation programs, however helps make connections among the potential overlapping layers that may be present in both trait El and wilderness orientation (Grout, 2009; 
Frauman \& Waryold, 2009; Bell, 2006; Jones \& Hinton, 2007; Gass et al., 2003; Gass, 1986).

Parallels among the survey instruments and the variables that they measure are examples of those overlapping layers. As an example, four distinctly independent articles (see Bobilya, Akey and Mitchell, Jr., 2009; Bell, 2006; Gass, 1986; Ewert, 1977) reported the use of four different survey instruments (Student Adaptations to College Questionnaire, Social Provisions Scale, Student Developmental Task Inventory and the Tennessee Self Concept Scale), all of which were found to have overlapping elements with the TEIQ, the instrument used to measure an individual's TEI score. These overlapping elements, although grouped to measure different factors or constructs, suggest that the mediating variables found may be related in some specific manner.

Specifically at hand, the TEI construct has been found to be a relatively effective variable in gauging the success of individuals in a variety of different situations (see Petrides, Frederickson \& Furnham, 2004; Petrides, Sangareau, Furnham \& Frederickson, 2006; Petrides \& Furnham, 2006). However, as elaborated by Petrides, Furnham and Mavroveli (2007), it can be hypothesized that these traits will stay relatively stable over time and could potentially be resistant to change because TEI has been placed within personality taxonomies. Through the use of interventions, students with a reported low El scores were shown to have marked improvement throughout a semester, assisting them in their transition to high school (Qualter, Whiteley, Hutchinson and Pope, 2007). Other studies (see Parker, Saklofske, Wood, Eastabrook, \& Taylor, 2005; Morris, Urbanksi \& Fuller, 2005) have also shown that El levels can be raised through increased college experience, participation in classes that increase emotional and social competencies, and activities that promote self-reflective behaviors. Calls for further 
research have also been given (see Jaeger and Eagan, 2007; Petrides, Furnham and Mavroveli, 2007; Mikolajczak, Luminet, Leroy and Roy, 2007), suggesting that the use of interventions be evaluated to determine if El can be developed, especially within first year students in a university setting(Jaeger and Eagan, 2007). Vandervoort (2006) has also suggested to the integration of El into existing course curriculum and development of specific classes that promote El development.

These statements, along with the benefits associated with wilderness orientation and the shared variables found in the multiple survey instruments, help give direction and purpose for this paper, laying the groundwork needed to move forward.

\section{Purpose of Study}

The purpose of this study is to identify the factors that contribute to the elicited changes in emotional intelligence that are afforded by participating in a wilderness orientation program, Adventure West Virginia. The results will help program coordinators better recruit university students at West Virginia University, and they will provide a means to which programming can be improved. 


\section{Research Questions}

1. Does an outdoor based pre-orientation program help students attain higher levels of perceived trait El upon completion of the program?

2. Can a study typology be derived from variables such as trip type, socioeconomics and motivations?

3. What specific trips contribute most to AWV students' TEl gain scores?

\section{Definition of Terms}

\section{Experiential Education:}

According to the Association for Experiential Education (AEE), experiential education isa fundamental philosophy and methodology educators utilize to fully engage with learners as they participate in the creation of curriculum that allows for the engagement of direct experiences and focused reflection that promote increased knowledge, developed skill and individual value (AEE, 2011).

In association with this definition, AEE presents other key aspects that are in association with the term and help develop and expand upon the above definition. AEE considers reflection analysis and synthesis as part of experiential education. Experiential learning also often requires participants to engage intellectually, emotionally, socially, soulfully and usually physically (AEE, 2007). These elements of participation also assist in the process of the learner activity posing questions, investigating, experimenting, being curious, solving problems, assuming responsibility, being creative and constructing meaning (AEE, 2007). The results can 
be considered personal and help construct the basis for future experiences and learning (see AEE, 2007), as would be applicable to most incoming freshmen in college.

\section{Orientation Programs (University 101):}

Orientation programs and freshmen seminars have been present in this country for more than 100 years (Gass, 1986; History of the First Year Seminar, 2011). Although there has been development throughout the many decades, the principle for many of these programs has essentially stayed the same. Orientation programs effectively are special courses offered to undergraduate students in order to help enhance their academic and social integration into college ("History of the First Year Seminar", 2011). The focus of many of these programs entails student retention, opening the lines between communication for both students and staff, creating a positive attitude towards college and to help students understand the essential purposes of higher education ("History of the First Year Seminar", 2011).

\section{Emotional Intelligence (EI)}

According to Salovey \& Mayer (1990), emotional intelligence "involves the abilities to monitor one's own and others' feelings and emotions, to discriminate among them and to use this information to guide one's thinking and actions." (p. 188). Other definitions of the construct come from Goleman (1995), who described El as being a set of valuable skills, abilities and competencies that differ in nature to that of IQ. The skill associated with El are that of motivating oneself, being persistent in facing obstacles and achieving goals, having the ability to motivate one's self, empathizing with others, controlling the fluctuations between moods, controlling the impulses or delaying gratification, thinking rationally and finally hoping (Goleman, 1995). 


\section{Trait Emotional Intelligence}

With historical roots in Thorndike's (1920) social intelligence and Gardner's (1983) theory of multiple intelligences (where he differentiates between interpersonal and intrapersonal intelligence), the construct of El has been expanded to incorporate a variety of fields in a variety of different research disciplines. One development involved the differentiation between two elements within El, trait and cognitive El-- both representing the new El construct. This development, however, came out of a response to the "haphazard development of $\mathrm{El}^{\prime \prime}$, as the operalization of the construct was dependent on the method in which it was measured (e.g. self-reporting vs. maximum performance testing) (Petridies \& Furnham, 2000, p. 314). With these issues at hand, Petrides and Furnham (2000) proposed the differentiation of El, as described above, placing the construct in alliance with the appropriate operalizational methods.

Trait El is also known as emotional self-efficacy. This construct represents the dispositions held by any person concerning their self-perceived abilities and is measured through self-reporting (Petrides \& Furnham, 2001). Trait El has been operationalized by being placed within personality frameworks, most notably the Big Five Framework, and uses the term "trait" in order to differentiate itself from cognitive abilities, which is exclusively associated with cognitive El, and consists of four factors (Well-Being, Self-Control, Emotionality, Sociability) that together comprise a global trait El score (Petrides \& Furnham, 2001). Through surveys that measure the dispositions comprising the affective aspects of personality, trait El has the ability to be a successful predictor of success for any individual in a variety of environments. 


\section{Cognitive Emotional Intelligence}

Usually used in comparison with trait emotional intelligence, cognitive emotional intelligence is the second half of the two constructs one's El ability (Petrides \& Furnham, 2001). Instead of being based on self-perceived abilities, cognitive El is concerned with the actual abilities and intelligence (Petrides \& Furnham, 2001). This construct also differs from trait in the way that it is measured. Instead of self-reporting, cognitive El uses maximum performances testing (much like IQ testing) to determine one's El ability (Petrides \& Furnham, 2001).

\section{Big Five Personality Framework}

As expressed by John, Naumann and Soto (2008), the "Big Five" personality domains are a consensus on the general taxonomy of personality traits. Although these traits do not represent any particular theoretical perspective, their origins were derived from multiple analyses used to group the terms individuals used to describe themselves and others (John et al., 2008). With this in mind, the Big Five has become an integrative function, as it represents the multiple and rather diverse networks that were constructed to help describe personality, all being placed within a communal framework (John et al., 2008). It is a fundamentally descriptive model of the factors that have been identified through factor analysis in relation to personality traits. Below are the factors encompassing the Big Five and their subsequent definition as provided by John et al. (2008).

1. Extraversion - Includes the traits of sociability, activity, assertiveness and positive emotionality all while implying an energetic approach.

2. Agreeableness - Includes the traits of altruism, tender-mindedness, trust and modesty. This domain contrasts a communal orientation with others with antagonism. 
3. Conscientiousness - Involves task and goal-directed behavior. This domain involves thinking before acting, delaying gratification and following norms with planning organizing and prioritizing tasks. Is also described as socially prescribed impulse control.

4. Neuroticism - Associated with negative emotionality. This domain involves contrasting against emotional stability and even-temperedness. Feelings of anxiousness, nervousness, sadness and tenseness are associated with this domain.

5. Openness - This domain encompasses the breadth, depth, complexity and originality of any certain individual's mental and experiential life.

\section{Freshmen/First-Year-Students (FYS)}

According to Grout (2009), a FYS "is a student who is enrolled in their first year of courses at any given university of college" (p. 8).

\section{Wilderness Orientation Programs}

Although the specific details encompassing many Wilderness Orientation Programs (WOPs) vary between schools, there is a fundamental framework among them. WOPs are physically challenging introductions to college. They provide small groups with the opportunity to participate in wilderness camping and adventure activities (Bell, 2008). These programs directly prepare students for college life (Bell, 2008). 
Specifically related to this study, Adventure West Virginia (AWV) has four different programs that are offered by WVU.

1. Explore - This program lasts eight days and provides students a variety of different places to visit and activities to participate. Rock climbing, hiking, sightseeing, backpacking and whitewater rafting are all incorporated in this trip ("Adventure West Virginia Web Site," 2010).

2. Odyssey - This program lasts 7 days and allows students to participate on the WVU challenge course. Aside from multiple days on the challenge course, students participate in hikes, canoeing, kayaking and camp at a local campsite near the challenge course facility (“Adventure West Virginia Web Site," 2010).

3. Wilderness - Lasting five days, this program take students backpacking through West Virginia. The program centralizes in the Monongalia National Forest and focuses on the Dolly Sods area ("Adventure West Virginia Web Site," 2010).

4. Habitat - Lasting seven days, Habitat places students in a Monongalia County Habitat for Humanity work site. Students help build homes for families and places less emphasis on the outdoor activities utilized in the other programs. Canoeing, rock climbing and hiking are also utilized throughout the trip ("Adventure West Virginia Web Site," 2010).

\section{Assumptions of the Study}

The assumptions of this study are:

1. All facilitators associated with the study will have had the same training in their particular field.

2. All students will have had the same experience with their particular program throughout the summer. 


\section{Limitations of the Study}

The limitations of this study are:

1. With the uniqueness of the program (Adventure WV) the results are only applicable to this program or the programs similar in their design.

2. The survey design relies on the self-evaluations of the participants. These evaluations may experience inflated scores due to a socially desirable response (SDR) (Hayashi \& Ewert, 2006).

3. A self-selection bias may have occurred. All participating students received a survey.

4. By having multiple uncontrollable variables present during the application of trips throughout the summer, many of the variables being measured may be affected. 


\section{Literature Review}

\section{College Orientation Programs}

Collegiate orientation programs and seminars have historical foundations dating over 100 years. Lee College and Boston University are credited as being the first institutions to implement either an orientation or seminar program that date back to the 1880s (Gass, 1986; History of the First Year Seminar, 2011). The popularity associated with such programs, however, has fluctuated periodically. A dramatic dissipation in program implementation occurred in the 1960s (History of the First Year Seminar, 2002). The popularity associated with orientation and seminar programs occurred in the 1970 s. As of $2006,84.8 \%$ of American colleges and universities reported some sort of first-year-seminar (History of the First Year Seminar, 2011).

These programs were developed mostly out of necessity, as the transitional difficulties faced by freshmen have traditionally been turbulent in nature (Bell, 2006). Coupled with the fact that students are the financial lifelines of their institutions (Jamelske, 2008), orientation programming has taken on a rather important role for both universities and students alike. Although variations exist, these programs were developed primarily to assist students as they ventured into their preparation for college. With an emphasis on the transitional difficulties associated with a new environment, the goals and objectives outlined for many orientation programs have been structured to help students as they prepare for their initiation to higher learning (Robison, Burns and Gaw, 1996). Gass (2003) also voices the importance of orientation programs, in that such courses have been found to create positive transitions for students as 
they enter their university setting. In addition to their importance, it has been found that orientation programs facilitate student development in three general areas: transitional processes, academic integration and personal and social integration (Robison et al. 1996). These areas are coupled with the orientation to other University programs including student services, specific academic programs, administrative regulations and expectations, student organizations and the institution's faculty and staff (Pascarella et al., 1986)

Before any initiation, students are often found troubled with the notion of leaving home and assuming a new role within a foreign environment (Pascarella et al, 1986). The stresses associated with this adjustment can be related to the patterns of persistence articulated by students, such as culture shock, in the form of significant social and psychological relearning, and may result from being introduced to new ideas, teachers, friends, beliefs, freedoms and opportunities (Pascarella \& Terenzini, 1991). These variables are coupled with the fact that students are diversifying in nature, as variations within student demographics may have conditional effects upon experiences and outcomes (Pascarella \& Terenzini, 2005).

In assisting with these multiple stressors, Merton (1957) suggests that orientation programs are anticipatory socialization processes, as these programs offer experiences through which students can become acquainted with the values, norms and behaviors in a new social setting (Pascarella, Terenzini, \&Wolfe 1986). This anticipatory socialization approach, as explained by Lane and Ellis (1968), is primarily a tool utilized by individuals as they try and adopt the attitudes, values and judgmental standards of the new class to which they wish to assimilate. Essentially, Pascarella and others (1986) found that orientation programs have 
significant effects on social integration and institutional commitment during college. These two variables ultimately were found to have the most significant impact on persistence within participating students, as the application of knowledge learned during orientation directly impacted the desire to persist. These findings are related to the study conducted by Sanchez, Bauer and Paronto (2006) in that students participating in a peer-mentoring based orientation program where found to have a higher satisfaction with the university and higher intentions to persist directly after the intervention. These studies are in contrast to the notion that students who show little commitment often become discouraged with their institution of choice, with this discouragement limiting their willingness to persist throughout college (Porter, 1990).

Robison, Burns and Gaw (1996) also give merit to university orientation programming, in that adequate information must be provided about a student's new environment if the transitional processes are to properly occur. According to Robison and others (1996), orientation programs help with the opportunity to meet new people within the campus community. These opportunities are not just limited to social fluctuations. Students also receive additional information that will assist in their planning for professional development and information that permits academic, social and personal growth (Robison et al., 1996). This information includes, but is not limited to, financial issues students often face, campus living options, student support services and information that can be communicated to parents, as they are typically part of the transitional process as well (Tinto, 1987). With a significant amount of student attrition happening during the first year, this information becomes crucial for student adaptation and success, especially with students experiencing high levels of stress due to the transitional experiences associated with college (Robison et al., 1996). Critical 
thinking is often a skill taught by orientation programs to limit stress since it is often presented as an application in understanding adaption (Tinto, 1987).

Adjustment to the academic environment is also a primary emphasis for many orientation programs, with many providing services and support to students. On many occasions, the institutions academic reputation and available majors are often the variables chosen in the decision to attend a college (Sax, Astin, Korn \& Mahoney, 1995). This logic suggests that students want to learn about the academic programs offered within a university given that well informed decisions will guide their way toward higher learning. Still, students often come to college ill prepared for the required academic rigor that is acquainted with their institution and choice of major (Robinson et al., 1996). Nevertheless, to help promote an understanding of the academic structure represented within an institution, many orientation programs offer academic information as a way of raising awareness and preparing students for their academic endeavors (Robinson et al., 1996). This information is often disseminated by faculty and academic administrators, providing incoming students and families an opportunity to meet school administrators as they distribute information about the college (Robinson et al., 1996). Typically, orientation programs cover a variety of topics, with many focusing on curriculum structure, graduation requirements, grading policies, university policies, placement testing and academic advising (Robinson et al., 1996). This type of advising allows students to form a bond with their chosen instructor, promoting a relationship that will assist students as they gain information about the university and its established policies (Gardner \& Hansen, 1993). 
In gauging the academic and retention effects students' gain by participating in orientation programs, Jamelske (2008) found that both GPA and retention rates increase as student participate in a goal compatible program. Essentially, the goal compatible approach classified groups that were in adherence to the specified goals established for the orientation program. By adhering to the goals set forth, these classes were able to show significant gains for students in both retention and GPA, as $87.8 \%$ of participating students returned following their first year (as compared to 81\%) and their subsequent GPA rose an approximate 0.160 points higher (Jamelske, 2008). These findings help give merit to the notion that orientation programs, when properly facilitated, offer students an environment in which they can develop academic and transitional knowledge in relation to their new institutional environment.

In addition to the transitional and academic information provided to students, orientation programs also disseminate information concerning the social environment associated with the given school. This dissemination is important in that it helps foster emotional support, often equivalent to family relationships, which in return facilitates a student's decision to stay at a university (Wilcox, Winn \& Fyvie-Gauld, 2005). Traditionally, institutional values, norms, support services and the expectations of community members are covered during orientation programming, giving students a solid understanding of the social structure within and around campus (Robinson et al., 1996). Orientation programming also serves as a time many universities strive to raise awareness in alcohol use, school diversity, personal safety, student led organizations, professional development, service learning (helping with transition and the connection to campus)and other student concerns that may be specific to the individual institution (Robinson et al, 1996). Individuals participating in the orientation 
programming also receive opportunities to meet other new and current students, faculty and staff and build a sense of community. These interactions facilitate the relations that help explain the university community, which in return may explain the behavioral expectations situated within the university setting (Robinson et al., 1996). These notions are supported through the findings of Hausmann, Schofield and Woods (2007). They suggest that in peergroup interaction, exchanges with faculty and peer and parental support have a direct impact on a student's sense of belonging at his or her chosen university. This further suggests that the early social experiences that are often confronted by students, and the consequent social support they receive, are important aspects to students' collegiate success (Hausmann et al., 2007). These findings also support the claims by Pascarella and others (1986). In their research, they found that the accelerated sense of belonging displayed by participating orientation students was a significant predictor to institutional commitment and intentions to persist (also see Hausmann et al., 2007). 


\section{Experiential/Adventure Learning}

The use of experiential learning has long been used throughout history to help individuals learn. The main objective, as noted by Gass (1985), is to create transferable experiences that can be applied to different situations throughout life. The roots to experiential/adventure learning can be seen through the expressions of Plato, as he celebrated the benefits associated with the outdoor experience, as they were observed to increase health and have values related to education (Hattie, Marsh, Neill \& Richards, 1997). By having an experience that can be directly related to future situations, and with parallels created between the two, participants are given the opportunity to connect and transfer their experience to other areas within their lives (Gass, 1985).

Being one of the main figures within the experiential profession, Kurt Hahn is given credit or developing the modern adventure education model (Hattie, et al., 1997). His model has led to the development of today's Outward Bound schools, as his initial work focused on assisting sailors in survival techniques as they spent time in the Atlantic Ocean (Hattie, et al. 1997). These schools are now viewed as benchmarks around the world, as they primarily focus on character, challenge, service and physically demanding activities (Hattie et al., 1997). The group and trip characteristics usually associated with these experiential/adventure education experiences often include a wilderness setting, a small group of usually less than 16 , a list of physically and mentally challenging activities that often incorporate teambuilding and decision making, a trained leader and a duration consisting of approximately two weeks (Hattie et al., 1997). 
Aside from Kurt Hahn, John Dewey also holds merit within the experiential community, with his philosophical work in education framing the approach and groundwork needed to advance the application of quality experiences in education. Overall, Dewey championed the idea of experience within the educational process, as he argued the social aspects related to learning were situated throughout the entire educational cycle (Dewey, 1938). Although Dewey (1938) cautioned that experiences may actually be counteractive to a quality education, with miss-educative experiences preventing development, his work ultimately guided the thoughts and actions for revolutionary approaches toward teaching. His notions emphasized that experiences play a huge role within the cognitive processes of a learner, with quality interactions mediating the role in promoting desirable future interactions (Dewey, 1938). It was communicated that learning activities should be structured in order to provide an experience that not only stimulates learners within the curriculum, but also provides avenues for future application of knowledge (also known as the experiential continuum). Dewey (1938) argued that an environment for quality interaction is necessary for adequate learning, with students actively creating learning scenarios alongside the teacher. Ultimately, Dewey (1938) saw education as the means for students to construct their full potential as they pursued the continuation of knowledge and the greater good. Overall, Dewey transcended the approach many experiential idealists have pioneered, as his fundamental assertions have guided the approach to the 'new education.'

Paralleled along with John Dewey and Kurt Hahn, David Kolb (1984) has also been given credence in developing and promoting the idea of experience in education. Much like Dewey, Kolb spoke of the importance of experience in education, with much of his work focusing on the 
development of the experiential learning model so widely used within the outdoor field today. Although not specifically developed for outdoor programming, Kolb (1984) expressed the model as reflecting the central role experience plays within the learning process. Rather than rivaling the cognitive or behavioral aspects of learning, Kolb's model is a holistic assimilation of the various aspects of learning which include experience, perception, cognition and behavior (Kolb, 1984). The basic assumption of the model is that ideas are not fixed and immutable elements of thought, but rather are formed and re-formed through multiple experiences. This also ascertains the notion that two thoughts are never the same, with the experience intervening and alternating the any initial approach (Kolb, 1984). Knowledge is continuously derived from the experiences of the learner and tested out in the subsequent activities following the lesson. This notion implies, however, that all learning is relearning, with individuals continuously involved within the moment as they gain and modify new notions and thought (Kolb, 1984). These thoughts are often facilitated by conflicts, in that individuals must mediate between incompatible viewpoints of the world. These conflicts are essential in that they move the experiential process forward, with each individual needing to involve themselves fully, openly and with bias in new experiences. These skills are further explained as being concrete experience abilities (CE), reflective observation abilities (RO), abstract conceptualization abilities (AC) and active experimentation abilities (AE). With the environment involved within a transactional agreement with the individual, both in subjective and personal sense, the experiential learning model takes effect as an educational process (Figure 1)). 


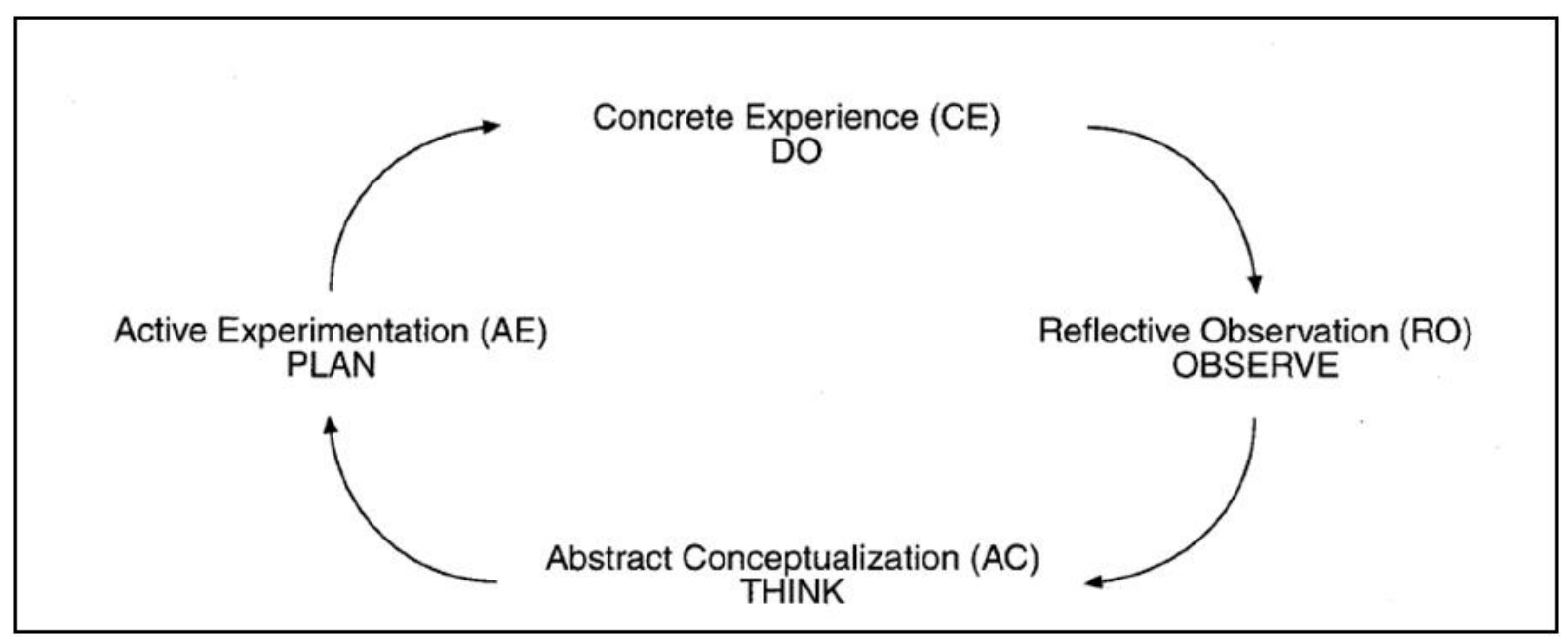

Figure 1: Kolb's Four Stage Experiential Learning Cycle. Adapted from Kolb (1984).

The benefits of the theoretical developments elaborated above are often explicit throughout the literature.

Using meta-analysis, Hattie and others (1997) examined the major outcome variables of academics, leadership, self-concept, personality, interpersonal and adventuresome in relation to adventure education and Outward Bound. This study examined the impacts reported in 96 studies (1,728 effects and 12, 057 participants) that were published over a 26 year period spanning from 1968 and 1994. Hattie and others (1997) found an overall standardized effect size of 0.34 , translating into a small to moderate effect. In their study, they concluded that although moderate ES where found and notable outcomes were derived, a great deal of variability existed between all the studies incorporated with the research.

In addition to the outcome variables examined by Hattie and others, (1997), the idea of self-efficacy also perpetuates through the research on experiential education. Grout (2009) found that, upon completion of a challenge course based orientation program, students who 
were exposed to an integrated curriculum (i.e., challenge course based activities rooted within a university curriculum) reported a significantly higher self-reported self-efficacy score. This compliments the findings of Paxton and McAvoy (2000), in that they reported upona wilderness-based Outward Bound program had positive benefits for individuals before and after their participation. Through their study, Paxton and McAvoy (2000) found that participants were able to raise their self-efficacy through the transference in abilities learned while in the wilderness. This study was also longitudinal and included a control group. That is, the participants of the Outward Bound model were surveyed three separate times (pre, post and 6 months later). The results indicate that the Outward Bound participants elevated their self-efficacy levels longitudinally over the 6 months span, with the control group experiencing no significant gain (Paxton \&McAvoy, 2000). Other self-efficacy findings can be found within the literature including Propsts and Koesler (1998), Richardson (2003), Harrison and McGuire (2006) and Berman and Berman (1996).

Outside of self-efficacy, other variables have been found to be impacted through experiential education. Neill (2008), Garst, Scheider and Baker (2001); Smith, Strand and Bunting (2002); and Griffin (2003) all report significant gains through research, with the use of experiential methodologies. In summary, life effectiveness, spiritual growth, moral reasoning and self-perception were shown to be impacted, giving credence to the experiential components examined earlier by Hahn, Dewey and Kolb. 


\section{Wilderness/Outdoor Orientation Programs}

Wilderness orientation programs are offered in various forms throughout the nation to help colligate freshmen become well prepared for their transition to college. Starting with Dartmouth in 1935(Hooke, 1987, as cited in Frauman \& Waryold, 2009), these programs have used the outdoors to help facilitate the students as they begin to integrate into their new university setting (Berman \& Berman, 1996). By utilizing an outdoor setting to simplify the initiation of students into a college setting, these programs routinely integrate innovative attempts to facilitate the adjustment struggles faced by many collegiate freshmen (Berman \& Berman, 1996). These programs involve a range of activities (e.g., backpacking, canoeing, climbing, ropes course), with a various number of participants (4 to 1,080 people), time periods (1 to 30 days), and cost for participation (\$0 to \$1050) (Bell, 2008; Berman \& Berman, 1996).The approach associated with each program is also diverse in philosophy and mission. With this in mind, recreational, educational, developmental, therapeutic and environmentally driven programs have been identified, with developmental programs receiving the most attention. (Neill, 2008)

Many studies (see Gass, 1986; Gass, Garvey \&Sugarmen, 2003; Bell, 2006; Jones \& Hinton, 2007; Grout, 2009, Bell \& Holmes, 2011; Bell, in press) have provided evidence of the benefits associated with outdoor orientation programs. For an example, Gass (1986) conducted several longitudinal studies measuring the impacts students received after they went through a wilderness orientation program. The findings associated with the study showed that the students who participated in the program faced a fare better retention rate compared to the control group (Gass, 1986). Gass and others (2003) revisited the same students 17 years 
later in a follow-up study gauging their reflections of their wilderness orientation experience.

The reports showed that the participants recalled positive memories from their experience and directly connected their decision making with items experienced while in the program (Gass, et al., 2003).

In measuring the relationship between preorientation programs and social support, Bell (2006) focused on measuring the elicited changes found within students in comparison to a host of programs. Essentially, Bell (2006) utilized the Campus-Focused Social Provisions Scale (CF-SPS) to gauge the level of social support students had within two distinct universities, Princeton and Harvard. The SPS hosts six distinct factors including attachment, social integration, reassurance of worth/competence, reliable alliance/tangible support, guidance and opportunity for nurturance (Bell, 2006). The results of the study found that participants who took the wilderness orientation program had higher mean scores in comparison to the study participants who did not attend a preorientation program, resulting in a statistically significant finding $(p<.001)$ (Bell, 2006). The findings also indicated that the wilderness based programs did show significant increases in all 6 social support sub factors, although not significantly higher than the other orientation programs (Bell, 2006).

In evaluating the impacts of a wilderness orientation program, Frauman and Waryold (2009) utilized the Life Effectiveness Scale (LEQ) to measure how a 4-day wilderness based program faired in preparing students in contrast to nonparticipating students. The First Ascent Program of Appalachian State University (ASU) was used for this study. Three incoming freshmen groups that participated in the First Ascent Program were compared with a control 
group (Frauman \& Waryold, 2009). The Life Effectiveness Questionnaire was used to evaluate the perceived changes students gained throughout their first semester in college. A pre-test and post-test method was used, as students were prompted to take an on-line survey immediately before the trip and subsequently two weeks into their first semester of college and at the end of the semester (Frauman \& Waryold, 2009). The study concluded that the First Ascent-only groups had main effect gains when compared to the control group. These findings suggest that by participating in wilderness based orientation programming; students increase their perceived life effectiveness (Frauman \& Waryold, 2009).

In conducting a two phase study pairing, an outdoor orientation program and a traditional first year experience (FYE) program, Bell and Holmes (2011) and Bell (in press) also found evidence supporting the application of outdoor orientation programming. In essence, Bell (in press) utilized the First Year Initiative (FYI) survey to investigate the differences in effect associated with the two orientation styles. Although the traditional FYE yielded significant and successful outcomes, as compared to other comparable programs, it was concluded that the outdoor orientation program achieved scores equal to or higher than the students participating in the traditional FYE for all 15 factors within the FYI. Two items were also found to be of special interest, however, with the outdoor orientation program outperforming the traditional FYE. In summary, the students rated the outdoor based orientation program higher in improving connections with peers and improving their knowledge of wellness.

In phase two of the study, Bell and Holmes (2011) focused primarily on the qualitative data. Their efforts specifically focused on the two survey outcomes. In all, Bell and Holmes 
(2011) employed the usage of reflection papers participants completed as part of their outdoor orientation experience. Student responses were coded based on the two items found to have the highest effect size rating. Nearly all papers were found to have some response related to the concept of peer connection, with uniform response rates found among all demographic categories. These rates were correlated with the dynamic structure of the outdoor orientation experience, and the authors suggested that the mediation of occurrence facilitated the concepts of trust, curriculum delivery (experientially laden with the transference of knowledge) and social support.

Other studies such as Grout (2009), Ewert (1977), Austin, Martin, Mittelstaedt, Schanning and Ogle (2009), and Bobilya et al. (2009) have also shed light on the benefits that are associated with wilderness orientation programming. In all, many predictor variables have been shown to increase as individuals participate in wilderness orientation programming. In reference to the items listed above, these variables include spiritual growth and self-efficacy, to sense of place and student self-concept. 


\section{Emotional Intelligence and Trait Emotional Intelligence}

Even though it is a relatively new construct, the El concepts have developed over many years. Thorndike (1920) (as cited in Salovey \& Mayer, 1990) was the first to coin the phrase "social intelligence", referring to the ability of people to act mindful of others in social situations, as they took emotionally laden information and acted upon it. This definition, however, was expressed in a rather negative connotation. Many applied "social intelligence" as a way to manipulate individuals and to persuade them to do unwanted tasks (Salovey \& Mayer, 1990). Adding to the fact that social intelligence was rather hard to quantify, momentum in the construct died until the early 1990s. With increased interest in the notion that emotions played a key role in our actions as people, Salovey and Mayer (1990) defined the term emotional intelligence as "the ability to monitor one's own and others' feelings and emotions, to discriminate among them and to use them information to guide one's thinking and actions" (p. 189). With this definition, they argued that life tasks were filled with emotional information and the individuals differed in their ability to assimilate and express this information appropriately.

They also incorporated Gardner's theory of multiple intelligences (1983), as they postulated the fact the El had a home within personal intelligence as it incorporated both interpersonal and intrapersonal abilities.

Further development within the construct included auxiliary popularization championed by Daniel Goleman. With both his books outlining the construct (also see Goleman, 1995; Goleman, 1998), he delineated El and proposed the impacts associated with the intelligence. In all, Goleman $(1995,1998)$ popularized the idea of El going above and beyond the applications 
of IQ. His initial ascertains pertained mostly to the notion that EI mediated the difference between successful and less successful individuals. Through Goleman, El was pitched as a legitimate intelligence, suggesting one's ability to negotiate emotions deserved attention. The qualities of El, according to Goleman, laid the groundwork for star performers and often demonstrated that qualities associated with El helped make up the largest portion of excellence.

As indicated above, this relatively new construct has seen much development, including multiple definitions of the term. Essentially, there have been three levels of El distinguished within the literature, ranging from the most conceptual to the most applied (Mikolajczak, Petrides, Coumans \& Luminet, 2009). The first refers to the complexity and depth of the conceptual-declarative emotion knowledge that has surfaced in recent literature. The second level most notably refers to the emotion-laden abilities associated with multiple scenarios. Finally, the third level refers to the emotion-related dispositions, also called traits, which differentiate individuals in how they utilize the emotion-laden abilities inherently found in each person (Mikolajczak et al., 2009).

Perhaps the best definition considers the differentiation between the two elements within El, trait and cognitive. Trait El (also known as emotional self-efficacy) and cognitive EI represent the two constructs that exist in terms of measuring one's El ability (Petrides \& Furnham, 2001). The latter represents the dispositions held by any person concerning their selfperceived abilities and is measured through self-reporting, whereas the former is concerned with the actual abilities held within any given individual and is only measured through 
maximum performance testing (Petrides \& Furnham, 2001). Trait El has been operationalized within personality frameworks, most notably the Big Five Framework, and uses the term 'trait', to differentiate from cognitive abilities, which is exclusively associated with cognitive El. This construct also consists of four factors (Well-Being, Self-Control, Emotionality, Sociability) that add together to comprise a global trait El score (Petrides \& Furnham, 2001). Empirical findings also suggest a difference, with very low, often non-significant, correlations found between the measures of trait El and ability El (Petrides, Furnham \& Mavroveli, 2007).

Outside of the statements above, where it is communicated that the multiple constructs of El have been complementary in nature, a drastic division between the two models has been identified. According to Petrides and others (2007), the operationalization of ability El is problematic given that the subjectivity of the emotional experience negates its implications. Petrides and others (2007) argued that the inadequacy of ability El stems from the attempt to incorporate items that are not truly measurable to the objective nature of emotions. This notion is well presented by Petrides and others (2007), as "the entire intrapersonal component of El seems to be impervious to maximum-performance measurement because the information required to score as correct or incorrect answer to the items like 'I am aware of my emotions as I experience them' is available only onto the individual who provides the answers" (p.151). A more explicit analysis of the scientific perspective related to the implausibility of ability El is provided by Brody (2004).

Although Goleman championed the idea of El as an intelligence (ability El), it can be argued that Petrides and Furnham have postulated the advancement of trait El, with their work 
defining the construct and operationalizing it within scientifically sound practices. Both Petrides and Furnham differentiate ability and trait El, suggesting the former is an effective measurement tool of El and its elicit impact upon individual performance. There are many examples (see Petrides et al, 2007; Petrides, Pita \& Kokkinaki, 2007; Petrides, Furnham \& Frederickson, 2004; Petride s\& Furnham, 2001; Petrides\&Furnham, 2000) detailing the work done in order to properly validate the construct of trait El. These works assist in giving merit to the scientific soundness related to this approach.

Overall, mainly through the work of Petrides, the idea of trait El has been recognized and accepted as a measurement of El. This is portrayed with the placement of TEI within the lower levels of personality frameworks, as it takes into effect and stays consistent with the existing models of individual differences (Petrides et al., 2007). Congruent with the subjective nature of emotions, this placement also does not encounter the conceptual inconsistencies facing ability El. Discriminate and incremental validity of the construct has also reported, as trait El has been shown to be fundamentally different than that of ability El (Petrides, PerezGonzalez \&Furnham, 2007). Essentially, trait El postulates that with the dynamic nature of emotionally laden reactions situated within individual responses, only the measurement of selfperceived abilities allow for the proper measurement of one's ability to regulate and utilize emotions (Petrides \& Furnham, 2001).

In order to develop the sampling domain for the construct, however, a content analysis on the previous literature was conducted. Based on the various operationalizations of the trait El construct, Petrides and Furnham (2001) took the salient facets associated with each 
approach (Table 1), and incorporated them in the Trait Emotional Intelligence Questionnaire (TEIQ). The rationale for this was to incorporate the core elements that were common among all operationalizations, including them within one model. This sampling domain is included within the survey instrument for trait El, the Trait Emotional Intelligence Questionnaire (TEIQ). Each factor, facet and the perceived thoughts of those individuals who score themselves as high are located below. 
Table 1: The factorial and subscale sampling domain for trait EI

Factors\& Facets

High Scorers Perceive Themselves as...

1. Well Being
a. Self-esteem
a. Successful and self-confident
b. Trait happiness
b. Cheerful and satisfied with their lives
c. Trait optimism
c. Confident and likely to "look on the bright side" of life

\section{Self-control}
a. Emotion regulation
a. Capable of controlling their emotions
b. Stress management
b. Capable of withstanding pressure and regulating stress
c. Impulsiveness
c. Reflective and less likely to give into their urges

\section{Emotionality}
a. Emotion perception (self and others)
b. Emotion expression
c. Relationship skills
d. Empathy
a. Clear about their own and other people's feelings
b. Capable of communicating their feelings to others
c. Capable of having fulfilling personal relationships
d. Capable of taking someone else's perspective

\section{Sociability}
a. Social competence
a. Accomplished networkers with excellent social skills
b. Emotion management (others)
b. Capable of influencing other people's feelings
c. Assertiveness
c. Forthright, frank and willing to stand up for their rights

The following subscales do not belong to any particular factor and are directly included in the total score

\begin{tabular}{ll} 
Adaptability & $\begin{array}{l}\text { Flexibility and willing to adapt to new } \\
\text { conditions }\end{array}$ \\
Self-Motivation & $\begin{array}{l}\text { Driven and unlikely to give up in the } \\
\text { face of adversity }\end{array}$ \\
\hline
\end{tabular}




\section{El and Trait El Benefits}

The benefits associated with the constructs of El have been identified, most notably trait El which is now beginning to gain acceptance as predictor variables of student success. Traditionally, according to Jaeger and Eagan (2007), the viewpoint of many universities has been that the ACT (American College Test) and the SAT (Scholastic Aptitude Test) were the best indicators for admission and performance in college. This thinking, however, has been questioned, given the acceptance of El as an evaluative measure used by universities. For the most part, the transition to college has been a difficult task for many incoming freshmen. The pressures associated with moving to a new area, making new friends, entering a new social and cultural environment and becoming independent can be stressful for any first time college student (Pascarella \&Terenzini, 2005; Parker, Summerfeldt, Hogan \&Majeski, 2004). These issues often leave many questioning what measures would be most effective in stationing students toward success.

As mentioned before, these variables are coupled with the fact that students are diversifying in nature, as variations within student demographics are found to have conditional effects upon outcomes and experiences (Pascarella \&Terenzini, 2005).These statements help frame the notion that individuals are markedly different in the extent to which they experience, attend to, process and utilize affect-laden information in relation to intra-personal or interpersonal situations (Petrides \&Furnham, 2003). These statements, although lofty, help focus the approach needed in order to fully understand the dynamic nature of affect laden perceptions and the benefits of El. 
To help in this transition process, nonetheless, research has shown that raised levels of El may have the ability to help students cope as they make the transition into a new environment. In testing the ability of high school students to make a successful transition into college, Parker and others (2004) found evidence supporting the notion that high El levels helped predict success at the academic level for students in college. Parker and others (2004), through the use of a self-evaluative El survey, collected data on the El levels of selected students and then tracked their academic progress throughout the semester. Although the initial analyses associated with the total sample were found to be poor indicators of academic success, select variables associated with El (i.e., intrapersonal skills, stress management and adaptability) were found to be strong indicators of student academic success. These variables were found to explain 8 to $10 \%$ of the variability in their first year GPA, proving to be a stronger predictor than that of a high school GPA (Parker et al., 2004). Deeper analyses also indicated that when students were split between highly successful and low performing individuals, the traits associated with high El were found to be strongly associated with academic success (Parker et al., 2004). These findings help provide insight to the types of benefits associated with elevated El levels, especially as a mediating variable for low performing students in academic situations.

In addition to the finding of Parker and others (2004), Qualter and others (2007) discovered that through an intervention program, low scoring El students were able to increase their overall El score. The premise of this study revolved around the notion that TEI operates as a mediating variable for success, with the construct facilitating the coping strategies for adolescents transitioning into a high school environment. Through the use of a program 
designed to support the development of El skill and application, Qualter and others (2007) conducted a study to see if high El levels interceded the transitional issues of students and whether it was possible to effect positive changes in El through an intervention program. This study employed the application of a control group to compare and contrast the results of the EI intervention group. The results of the study indicated that through longitudinal testing (two tests over a 9 month period) three distinct groups were found based on pretest scores, with low, average and high scores reported via the standard deviation of responses. Higher levels of El were found to assist a student's ability to cope with transition, supporting the claims above. These students were found to more likely be successful as they persisted throughout the school year, requiring less attention with behavior, self-worth, GPA and school attendance (Qualter et al., 2007). The intervention also had significant impacts on low scoring El students, raising their score and outscoring the control group. These finding support that notion that self-reported EI scores can be raise significantly, impact student's persistence through school.

Given the findings above, Petrides and others (2004) also have contributed to the literature associated with El and the elicited impacts related to its application. In all, Petrides and others (2004) focused primarily on the role TEl played in the academic performance and the application of deviant behavior within a sample of 650 secondary education students. Their results support the notion the TEI can be considered a mediating variable, with high reporting TEl students performing superiorly over low reporting TEI individuals. These finding were based on the evaluation of multiple variables with truancy, unruliness and scholastic achievement. Low-reporting TEl individuals were hypothesized to perform substandard in relation to highreporting individuals simply due to the nature that "vulnerable or disadvantaged individuals are 
more likely to experience stress and emotional difficulties during the course of their studies" (Petrides et al, 2007, p. 279).The results supported the notion that high TEl scores helped moderate the effects of IQ. This is synthesized through the combination of core items within the study, with composite English scores, total number of absences and the instances of expulsion of school all taken into account. (Petrides et al, 2004). These results again support the notion that El, most notably $\mathrm{TEI}$, can help moderate the applications of students with stress levels and anxiety condensed through the application of highly perceived abilities. The results of this study, and subsequently others related to Petrides et al. (2004), can perhaps be best visualized in Figure 2 below. Essentially, with high TEI scores, low IQ individuals are better able to combat increased pressure particularly those associated with academic performance.

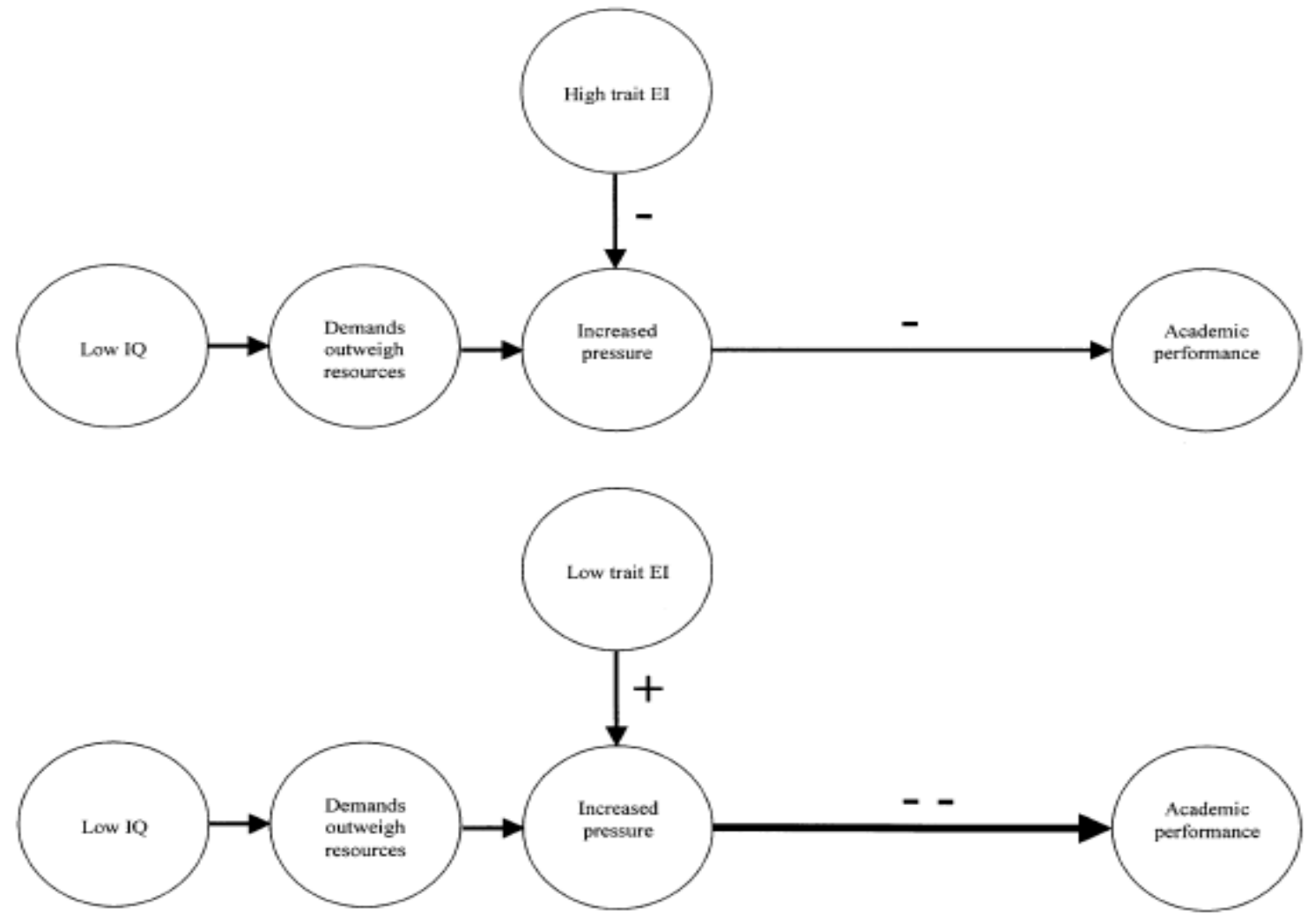

Figure 2: The mediating role of TEl in scholastic success. Adapted from Petrides et al. (2004). 
In addition to the studies presented above, other works have shed insight into the applications of TEI as a mediating variable, most notably in reference to academic and scholastic situations. One such example is the work completed through Petrides, Sangareau, Furnham and Frederickson (2006), as they investigated the role TEI played in facilitating the peer relations of students at school. Through their work, Petrides and others (2006) found that through peer evaluations, high TEl students were more likely to receive nominations for cooperation and leadership and were less likely to receive nominations for disruptive, aggression and dependence. Qualter, Gardner, Whiteley, Dudiak and Pope (n.d.) also give credence to the fact that TEI enables the application of successful behaviors, especially in relation to retention in school. In all, Qualter and others (n.d.) give a synthesis of ideas supporting the notion that TEI, or emotional self-efficacy, can assist in serving student retention as they continue to persist throughout their time in school. This persistence, both social and academic, is credited to the fact that high scoring TEI individuals are often motivated to use their self-perceived abilities, especially when prompted to seek help. Qualter, Whiteley, Morely and Dudiak (2009) and Parker, Hogan, Eastabrook, Oke and Wood (2006) also provide resources and insight into the applications of El and student transition. Their works sustain the notion that retention is supported through reported high El levels, with students negotiating the transitional issues effectively through their emotionally laden perceptions.

Outside of the academic situations where TEI can be applied, many other studies have displayed the overall practicality of the construct, as it continually displays its mediating effects. Essentially, trail El has been found to be negatively associated with depression (Ciarrochi, Deane \& Anderson, 2002), anxiety (Ciarrochi, Chan \&Bajgar, 2001), phobic and obsessive 
symptoms (Mikolajczak, Luminet, Leroy \& Roy, 2007), personality disorders (Petrides, Perez-

Gonzalez \&Furnham, 2007), and burnout (Mikolajczak, Menil \& Luminet, 2007). These negative correlations continue to build support for the applications of TEI. 


\section{Method}

The purpose of this study is to measure the perceived gains in trait El for students participating in the outdoor orientation program, Adventure West Virginia (AWV). This section will focus on the method and measures used to examine the perceived gains in trait El. The survey instrument, research design, treatment and data collection will be presented in this chapter.

\section{Survey Instruments}

\section{Motivational Measures}

The motivational scale used originates from the work done by Driver (1983), and incorporates some of the Recreation Experience Preference (REP) scales and represents most of the domains. In essence, this work incorporates a variety of domains, scales and core statements, all structured to measure preference for recreational experiences or motivations. These scales were used to measure individual's motivation for participation in an Adventure West Virginia trip. In all, 21 domains encompass the REP. In this study, however, researchers selected domains that they considered most relevant to the Adventure WV experience. Sixteen of the overall domains were chosen to be a part of the study, with every scale represented within that domain. The top correlated statement with the scale was chosen to be a part of the survey instrument. In all, 37 items were chosen, all measured using a 7 point Likert scale (1=Not Important to 7=Extremely Important) for the pretest. A four point Likert scale was used in the post survey instrument ( $1=$ Not at all Able to 4=Totally Able). The selected items are listed in Table 2 below. 
Table 2: Selected REP Domains, Scales and Core Statements

Domains and Scales

Core Statement

1. Achievement/Stimulation
a. Reinforcing self-image
a. To gain a sense of self-confidence
b. Social recognition
b. To have others think highly of you for participation
c. Skill development
c. To become better at a particular skill
d. Competence testing
d. To test your abilities
e. Excitement
e. To have thrills
f. Endurance
f. To test your endurance
g. Telling others
g. To tell others about the trip

\section{Autonomy/Leadership}
a. Independence
a. To feel my independence
b. Autonomy
b. To be my own boss
c. Control-Power
c. To control things

\section{Risk Taking}
a. Risk Taking
a. To take risks

\section{Similar People}
a. Being with friends
a. To be with members of your own group
b. Being with similar people
b. To be with people who enjoy the same things you do

\section{New People}
a. Meeting new people
b. Observing other people

a. To talk to new and varied people

b. To be with and observe other people using the area

\section{Learning}
a. General Learning
b. Exploration
a. To develop your knowledge of things here
c. Geography of area
b. To experience new and different things
d. Learn about nature
c. To get to know the lay of the land
d. To study Nature

\section{Enjoy Nature}
a. Scenery
a. To view the scenery
b. General nature experience
b. To be close to nature

\section{Introspection}
a. Spiritual
a. To develop personal, spiritual values
b. Introspection
b. To think about your personal values 


\section{Escape Personal-Social Pressures}
a. Tension release
a. To help get rid of some clutched up feelings
b. Slow down mentally
b. To have your mind move at a slower
c. Escape role overloads pace
d. Escape daily routines
c. To get away from the usual demands of life
d. To have a change from you daily routine

\section{Escape Physical Pressure}
a. Tranquility
a. To experience tranquility
b. Privacy
b. To feel isolated
c. Escape crowds
c. To be away from crowds of people
d. Escape physical stressors
d. To get away from the clatter and racket back home

\section{Social Security}
a. Social security
a. To be near considerate people

\section{Escape Family}
a. Escaping family
a. To be away from the family for awhile

\section{Teaching-Leading Others}
a. Teaching sharing skill
a. To teach your outdoor skills to others
b. Leading Others
b. To help direct the activities of others

14. Risk Reduction
a. Risk Moderation
a. To be near others who could help if
b. Risk Avoidance
you need them
b. To be sure of what will happen to you 


\section{Trait Emotional Intelligence Questionnaire-Short Form (TEIQ-SF)}

The TEIQ-SF is a short version of the original TEIQ and was specifically designed to measure global trait El (Petrides \&Furnham, 2006, Cooper and Petrides, 2010). This 30 item form incorporates two items from each of the 15 subscales associated with the TEIQ and uses a 7 point Likert scale (1=highly disagree to 7=highly agree) (Petride \&Furnham, 2006).These selections were made primarily based upon their correlation with the corresponding total subscale scores for each facet comprising TEI (Petrides \&Furnham, 2006). This procedure was used in order to help ensure that the adequate internal consistencies and broad coverage of the sampling domain of the trait El construct were represented (Petrides \&Furnham, 2006).

Independent studies testing the incremental validly, criterion validity, internal consistencies, factor structure and certain criterion measures related to that of the full scale TEIQ show the survey is reliable and accurate way to measure the self-perceived emotional abilities of participants (Freudenthaler, Neubauer, Gabler \&Scherl, 2008; Mikolajczak et al., 2007). The four factors also "displayed a psychologically meaningful pattern of convergent and discriminate relations to self-assessed intra and interpersonal emotional abilities" (Freudenthaler et al., 2008, p.676). For the criterion measures, the TEIQ was positively related to life satisfaction and perceived quality of social support, negatively related to indicators of anxiety and depression and displayed incremental abilities in predicting coping styles, emotional reactivity, loneliness and personality disorders (Freudenthaler et al., 2008;Mikolajczak et al., 2007). Incremental validity has also been shown in relation to the personality trait taxonomies that house the construct of TEI within their lower levels, most 
notable being the Big Five and Giant Three (Mikolajczak et al., 2007; Petrides, Perez-Gonzalez and Furnham, 2007). Finally, the survey instrument was found not to be sensitive to age differences, nevertheless, significant gender differences were found between both male and female participants (Mikolajczak et al., 2007).

\section{Research Design}

For the purposes of this study, a quasi-experiential design was used, and all potential first year students going through the AWV program were asked to participate. This study was conducted throughout the summer of 2010 and incorporated all 25 AWV trips that were offered. For each trip, four leaders were assigned a variable group of first year students with instructions to lead various tasks and events. Each trip utilized an adapted core curriculum associated with the University 101 classes offered through WVU. This curriculum varies slightly within each program, as different elements associated with the various trips offer unique experiences for each student (Wilderness vs. Odyssey). The dependent variable associated with this study, trait EI, was measured twice via the TEIQ-SF survey. Pre and posttest surveys were administered, and each student was given the opportunity to participate. Program coordinators were trained under IRB regulations to help administer surveys. Although the entire program of AWV was gauged upon its effectiveness to elicit a change in self-perceived trait El, fundamental elements of each individual trip were also analyzed. This approach ensured the total program was evaluated in relation to its performance. As mentioned above, the study utilized a quasiexperimental approach. Non-randomized sampling was used in order to obtain a large enough sampling size and also to allow students to self-select their preferred AWV program. 


\section{Treatments}

Four different AWV programs were examined in this study (Table 3). These trips were offered several times throughout the summer, with many groups overlapping periodically. All trips were augmented by two distinct leadership groups, consisting of four leaders in each group. Odyssey, AWV's challenge course program, offers the same program eight times throughout the summer. Explore offers 8 different trips, Wilderness offers 5 trips and Habitat offers 4 trips (totaling 25 trips overall). Although the effectiveness of AWV as a whole was evaluated, the fundamental elements of each intervention program were considered in the data analysis. These treatments, however, were not randomly assigned, as each participate had the opportunity to select their own trip.

Adventure West Virginia, as mentioned previously, utilizes the same core curriculum administered for each University 101 class offered throughout WVU. These classes cover a variety of topics, all being applicable to the issues associated with first year students and their initial semester of college. Although the same core curriculum is found throughout the AWV program, each individual program custom delivers these topics in a variety of ways. As an example, the Odyssey WV program utilizes a mixture of high and low element structures to integrate curriculum through each specific trip, matching experiences within an experiential style while facilitating connections to the freshmen year. The other programs (Habitat, Wilderness and Explore) also integrate an experiential style to facilitate their programming. These experiences differ, however, with each program. Located below is a breakdown for each individual trip offered through AWV. An outline detailing the goals and objectives for WVU University 101 class are provided in the appendences. 
Table 3: Explanation of treatments within AWV

Trip Name

1. Odyssey
Trip Characteristics

Challenge course based trip located within the WVU Research Forest. Seven days of programming see the sequencing of low and high rope activities. Participants stay in a developed site. Approximately 22 students on each trip. Also visit Coopers Rock, the Monongalia National Forest and Tygart Lake.

\section{Explore}

Outdoor recreationally based programming that utilizes the application of white-water, rock climbing, hiking and camping to integrate curriculum experientially. Seven days of programming see participants visiting Chestnut Ridge, Coopers Rock, the WVU Challenge Course, the Monongalia National Forest, Spruce Knob and the New River National Recreation Area.

This trip sees the utilization of a local Habitat for Humanity worksite. Seven days of programming see participants experientially work adjacently with Habitat volunteers in constructing an actual house for a selected family within the Morgantown area. Students stay at the International House in downtown Morgantown. Tygart Lake, the Monongalia National Forest and the WVU Challenge Course are also visited.

\section{Wilderness}

Primarily based within the Dolly Sods Wilderness Area located inside the Monongalia National Forest. Five days of programming see three separate groups participate in primitive camping. Hiking and camping are the base activities for this trip, with students learning the basics in wilderness navigation, camping and survival all housed within experiential teachings and application. 


\section{Data Collection}

\section{Pre-test}

As mentioned above, all students participating in the AWV program were asked to participate in the study when they arrived at the start of the program. However, as a precursor for each trip, AWV conducts a sign-in procedure that takes place within the WVU Outdoor Recreational Center (ORC), a section within the Student Recreational Center (SRC). This area was used to administer the survey given it is a centralized location for each trip. The check-in process covers the expectations of the trip and an equipment check to ensure students have all the necessary items to participate. At the conclusion of this process, the program coordinator, most often a full-time staff employee or graduate assistant within AWV, conducts a final review of the group before they depart. The survey was administered during this time. Participants were briefed before their participation. The study was voluntary and confidential, and student participation in the survey had no impact on their grade in the AWV program. Students were asked to participate in the study. Upon completion of all check-in items, students were directed to their respective course director, where all pretest and IRB consent forms were located. A verbal confirmation was received from all the students who participated in the initial study, with all research conducted under the guidelines established by the Institutional Review Board (IRB). All data were collected in adherence to IRB requirements.

The completed surveys were administered and collected by each program director onsite. Students were given sufficient time to compete each survey. The pre-test did not interfere with any pre-trip programming or facilitation. The distribution of the survey concluded about 10 
minutes before preliminary programming. This approach minimized interference with trip dynamics and survey response bias.

\section{Post-test}

The post-test was administered in a way similar to the pre-test. Upon completion of the AWV program, students returned to the ORC to collect equipment before the students returned home. During this time, the post-test survey was administered to participating student. The surveys were gathered prior to the AWV closing ceremonies, were students were given the opportunity to say their final goodbyes, reflect and exchange information. This was done in order to reduce programming influence on survey responses and attrition (most students left immediately following the closing ceremonies). The completed surveys were collected by the program director on-site. All data were collected in accordance to IRB requirements.

\section{Data Analysis}

The quantitative data were coded and entered into SPSS 19.In total, 317 pre and post tests were deemed usable in this research project. Descriptive statistics and t-tests were used to summarize the sample profile (e.g., student demographics, and self-evaluated TEI mean scores).

Research Question 1: Does an outdoor based pre-orientation program help students obtain higher levels of perceived trait El upon completion of the program?

Along with the frequencies, mean-tests were applied to help gauge the overall elicited impact Adventure had upon the self-evaluated TEI scores. These t-tests were used to examine 
the differences between pre and post TEI scores. This analysis helped address the first research question of this study.

Research Question 2: Can a study student typology be derived from variables such as El, trip type, socioeconomics and motivations?

A varimax rotation factor analysis of motivational items was used as a data reduction technique. Items with loading scores greater than 0.40 were included in each factor. The interreliability of domain items were examined using Cronboch's alpha. The mean scores for each domains identified were reported for the aggregate sample. Pre-test TEI indices were created for each student by calculating the mean item scores for each of the four TEI factors. A TEI global score represents the overall mean of the 30 TEI items.

A student typology was created based on the pre-test TEI distribution of mean global scores. Distribution tertiles were used to define membership as low, medium, and high TEl. Analysis of variance and Chi-square tests were used to identify differences among the 3 groups of students. Variables examined included the motivational factors derived from the REP domains, scales and core statements. Those analyses helped address research question 2.

Research Question 3: What specific trips contribute most to AWV students' TEI gain scores?

TEI gain scores were calculated by subtracting post-trip TEI from pre-trip TEI scores. Analysis of Variance was used to determine if mean gain scores were dependent on AWV trip type. 


\section{Results}

This chapter presents the study results. Results are summarized for each research question specified in the introduction. Each section follows the basic outline of restating the research objective and outlining the results found. Each section includes the appropriate tables related to the given objective and report the statistical analyses associated with the section.

\section{Response Rate}

As indicated in Chapter 3, all students were solicited to participate during the check-in process for AWV. During this time, students were given the opportunity to voluntarily participate in the study. All programs examined were made up of 22 to 26 incoming freshmen. Although the majority of students were asked to participate, logistical challenges complicated the process and likely affected the response rate. This included dismissing the survey process 10 minutes prior to the start of the program. This was particularly true for all Wilderness programs, which started earlier at 8:00 AM. Surveys were also discarded if no post-test was completed.

In all, 317 students participated in the study out of a total of 576, resulting in an overall response rate of 55\% (Table 4). Further, the study included responses from 117 Explore students, 131 Odyssey students, 38 Habitat students and 31 Wilderness students. These numbers are proportionate to the total number of students that participate in each program. 


\section{Table 4: Response Rate for Survey Instrument}

\section{Student Profile}

Through the use of a demographic section located within the pretest packet, students were asked to report upon multiple demographic items in relation to the study. In all, seven specific questions were asked relating to demographics, with all being specified below (Table 5).

Gender -The distribution of male and female participation was fairly even. As a compilation of the entire studied sample population, 153 (48.3\%) males and 163 females (51.4\%) participated. Only one individual (.3\%) withheld their gender information.

Hispanic or Latino - Overwhelmingly, the majority of students associated themselves as not being Spanish or Latino. In all, only 5 participants (1.6\%) identified themselves as being either Hispanic or Latino. Only one participant (.3\%) did not answer the question.

Ethnicity - The majority of respondents identified themselves as being White (307 participants, 96.8\%). The remaining students were American Indian/Alaskan Native $(n=2,0.6 \%)$, Black/African American ( $n=3,0.9 \%)$, Native Hawaiian or other Pacific Islander $(n=2,0.6 \%$ ), and other (n-1, 0.3\%). Two participants withheld their ethnicity information (.6\%).

Home State- In being one of the more diverse variables associated with this study, the majority of students identified themselves as being from an "Other State". Of out-of-state students, $21.5 \%$ were from Pennsylvania (21.5\%), 9.7\% from Virginia, 7.3\% from New Jersey, 
6.6\% from Ohio and 6.0\% from Maryland. In all, 117 (36.9\%) of the respondents were from West Virginia. California, Connecticut, Delaware, Florida, Illinois, Kentucky, Michigan, Montana, New York, North Carolina, Tennessee, Texas and the District of Columbia were also represented within the sample.

Parents Who Attended College- For this sample, a relatively high percentage of students ( $n=249,78.8 \%$ ) reported having parents who attended college. Of those respondents, only $56(17.7 \%)$ indicated that their parents attended WVU. One student $(0.3 \%)$ did not respond to the question.

Service Learning Experience - A total of 174 students (54.9\%) indicated that they had some type of service learning experience before college. Eight participants (2.5\%) did not answer the question.

Extracurricular Activities - To help bring light into the number of students participating in extracurricular activities before college, an astonishing 301 students (95\%) reported participating is some extracurricular activity prior to college. Only five students (1.6\%) didn't answer the question. 
Table 5: Student profile characteristics (Gender, Hispanic or Latino, Ethnicity, Home State, Parents Who Attended College, Service Learning and Extracurricular Activities)

Frequency

Percent of Total

Gender $(n=316)$

Male

153

48.3

Female

Hispanic or Latino ( $n=316)$

Hispanic or Latino

Not Hispanic or Latino

Ethnicity ( $n=315)$

American Indian/Alaskan Native

2

.6

Black/African American

3

.9

Native Hawaiian or other Pacific Islander

2

.6

White

307

96.8

Other

Home State $(n=316)$

West Virginia

Other State

Parents Who Attended College $(n=316)$

Yes (WVU)

No

$249(56)$

67

$78.5(17.7)$

21.1

Service Learning Activities ( $n=309)$

Yes

174

135

56.3

No

43.7

Extracurricular Activities ( $\mathrm{n}=312$ )

Yes

No
96.5

3.5 


\section{Trip Satisfaction}

Two survey questions were included in the post-test questionnaire to help determine if AWV was satisfactory to students participating in the program.

Trip Satisfaction - The overall trip satisfaction for the entire AWV program was highly rated. Trip satisfaction was measured using a Likert scale $(1=$ Not at all Satisfied and $5=$ Extremely Satisfied). A large percentage (92.7\%) reported that they were either very or extremely satisfied with their program of choice, suggesting that the AWV program was successful with the application of programming.

Preparation for College - Much like trip satisfaction, the success of AWV in preparing students for college provides strong evidence that the programs are working. A total of 298 students $(98.7 \%)$ indicated that the program helped them prepare for college. This was measured with a nominal (yes/no) variable.

Table 6: Trip Satisfaction and Preparation for College

\begin{tabular}{lcc}
\hline & Frequency & Percent of Total \\
\hline Trip Satisfaction $(\mathrm{n}=316)$ & & \\
\hline Slightly Satisfied & 1 & 00.3 \\
Moderately Satisfied & 22 & 07.3 \\
Very Satisfied & 103 & 32.6 \\
Extremely Satisfied & 190 & 60.1 \\
Preparation for College $(\mathrm{n}=302)$ & & \\
Yes & & \\
No & 298 & 98.7 \\
\hline
\end{tabular}




\section{Research Question 1: Does an outdoor based pre-orientation program help students obtain higher levels of perceived trait El upon completion of the program?}

\section{Adventure WV and TEI}

This section addresses the first research question of the study. The analysis was conducted to examine the overall effectiveness of AWV in relation to the self-perceived TEI levels of each participant. Paired t-tests were used to compare pre and post TEI measures. .

TEI Item Mean Comparison - The mean comparisons between pre and post TEI measures are reported in Table 7. Respondents reported significant gains ( $p$-value $\leq .05$, twotailed) in 18 of the TEI items that were examined. The TEI items with the greatest gains include I often pause and think about my feelings (mean=0.666), I believe I'm full of personal strengths (mean=0.646), Expressing my emotions with words is not a problem for me (mean=0.497), I'm normally able to "get into someone's shoes" and experience their emotions (mean=0.457), and I feel that I have a number of good qualities (mean=0.449).

Factor Mean Comparisons - The mean differences between pre and posttest TEI domain scores were examined using paired t-tests (Table 8). Significant gains ( $p$-value $\leq .01$, two-tailed) were reported by students for all 4 TEI domains: Emotionality (mean=0.264), Sociability (mean=0.216), Well-Being (0.324), and Self-Control (mean=0.207). 
Table 7. TEIQ-SF Pre and Post Line Item Comparison

\begin{tabular}{|c|c|c|c|c|}
\hline Trait Emotional Intelligence Questionnaire - Short Form & Mean & $\mathrm{t}$ & $d f$ & Sig (2-tailed) \\
\hline Expressing my emotions with words is not a problem for me & .497 & 5.099 & 315 & $.000 * *$ \\
\hline I often find it difficult to see things from another person's viewpoint & .180 & 2.066 & 315 & $.040 *$ \\
\hline On the whole, I'm a highly motivated person & .403 & 5.909 & 312 & $.000 * *$ \\
\hline I usually find it difficult to regulate my emotions & .186 & 2.142 & 316 & $.033^{*}$ \\
\hline I generally don't find life enjoyable & .025 & 0.335 & 314 & .738 \\
\hline I can deal effectively with people & .372 & 5.156 & 316 & $.000 * *$ \\
\hline I tend to change my mind frequently & .104 & 1.199 & 316 & .232 \\
\hline Many times, I can't figure out what emotion I'm feeling & .063 & 0.663 & 316 & .508 \\
\hline I feel that I have a number of good qualities & .449 & 6.916 & 315 & $.000 * *$ \\
\hline I often find it difficult to stand up for my rights & .000 & 0.000 & 316 & 1.000 \\
\hline I'm usually able to influence the way other people feel & .429 & 5.592 & 316 & $.000 * *$ \\
\hline On the whole, I have a gloomy perspective on most things & .149 & 2.078 & 314 & $.039 *$ \\
\hline Those close to me often complain that I don't treat them right & .041 & 0.631 & 314 & .528 \\
\hline I often find it difficult to adjust my life accordingly to the circumstances & -.009 & -.104 & 316 & .917 \\
\hline On the whole, I'm able to deal with stress & .221 & 2.824 & 314 & $.039 *$ \\
\hline I often find it difficult to show my affection to those close to me & .041 & 0.402 & 316 & .688 \\
\hline $\begin{array}{l}\text { I'm normally able to "get into someone's shoes" and experience their } \\
\text { emotions }\end{array}$ & .457 & 6.060 & 316 & $.000 * *$ \\
\hline I normally find it difficult to keep myself motivated & .120 & 1.324 & 316 & .187 \\
\hline I'm usually able to find ways to control my emotions when I want & .309 & 3.683 & 316 & $.000 * *$ \\
\hline On the whole, I'm pleased with my life & .331 & 6.939 & 316 & $.000 * *$ \\
\hline I would describe myself as a good negotiator & .332 & 5.103 & 315 & $.000 * *$ \\
\hline I tend to get involved in things I later wish I could get out of & .028 & 0.334 & 316 & .738 \\
\hline I often pause and things about my feelings & .666 & 7.436 & 316 & $.000 * *$ \\
\hline I believe I'm full of personal strengths & .646 & 10.671 & 315 & $.000 * *$ \\
\hline I tend to "back down" even if I know I'm right & .101 & 1.202 & 316 & .230 \\
\hline I don't seem to have any power at all over other people's feelings & .076 & 0.887 & 314 & .376 \\
\hline I generally believe that things will work out fine in my life & .360 & 4.946 & 313 & $.000 * *$ \\
\hline I find it difficult to bond well even with those close to me & .180 & 1.888 & 315 & .060 \\
\hline Generally, I'm able to adapt to new environments & .291 & 4.153 & 315 & $.000 * *$ \\
\hline Other admire me for being relaxed & .391 & 5.311 & 316 & $.000 * *$ \\
\hline
\end{tabular}

\footnotetext{
${ }^{*}$ Paired t-test, two tailed $\mathrm{p} \leq .05$ - **Paired t-test, two tailed $\mathrm{p} \leq .01$
} 
Table 8. TEIQ-SF Pre and Post Factor Item Comparison

\begin{tabular}{lcccc}
\hline Trait Emotional Intelligence Questionnaire - Short Form & Mean & $\mathrm{t}$ & $\mathrm{df}$ & Sig (2-tailed) \\
\hline Emotionality & .264 & 7.167 & 311 & $\mathbf{. 0 0 0 ^ { * * }}$ \\
Sociability & .216 & 5.372 & 313 & $\mathbf{. 0 0 0}^{* *}$ \\
Well-Being & .324 & 9.285 & 307 & $\mathbf{. 0 0 0 ^ { * * }}$ \\
Self-Control & .207 & 4.972 & 316 & $\mathbf{. 0 0 0 ^ { * * }}$
\end{tabular}

*Paired t-test, two tailed $\mathrm{p} \leq .05$ - **Paired $\mathrm{t}$-test, two tailed $\mathrm{p} \leq .01$

Global TEI Mean Comparison - A paired t-test was used to examine the mean

difference between pre and post Global TEI scores (an index that includes all TEI items) (Table 9). Again supporting the notion that AWV contributes to the development of TEI, the result was significant (mean=0.237, $\alpha=.001)$.

Table 9. TEIQ-SF Global TEI Pre and Post Comparison

\begin{tabular}{lccccc}
\hline Trait Emotional Intelligence Questionnaire - Short Form & Mean & $\mathrm{t}$ & $\mathrm{df}$ & Sig (2-tailed) \\
\hline Global TEl Score & .237 & 8.716 & 296 & $\mathbf{. 0 0 0 ^ { * * }}$ \\
\hline
\end{tabular}

*Paired t-test, two tailed $\mathrm{p} \leq .05$ - **Paired t-test, two tailed $\mathrm{p} \leq .01$ 


\title{
Research Question 2: Can a study student typology be derived from variables such as
} TEI, trip type, socioeconomics and motivations?

\author{
AWV Student Typology \\ To address research question 2 , a study typology was created to help better understand the \\ type of student who participates within the AWV program. Using the Global TEI pretest scores, we \\ identified 3 groups of students (high, medium, and low TEI). Chi-square tests and ANOVA were used \\ to identify other differences between the three groups including AWV trip type, socioeconomics, and \\ motivations to participate in AWV.
}

TEI - Based Segmentation- All of the AWV students participating in the study were broken up into tertiles based on their pre-test Global TEI scores (Figure 3). Each group represents 33\% of the sample. Each group was labeled low, medium, and high TEI. The low group's Global TEI scores ranged from 3.65 to 5.04. The medium group's Global TEI scores ranged from 5.06 to 5.52. Finally, the high group's TEI scores ranged from 5.06 to 5.52 . 


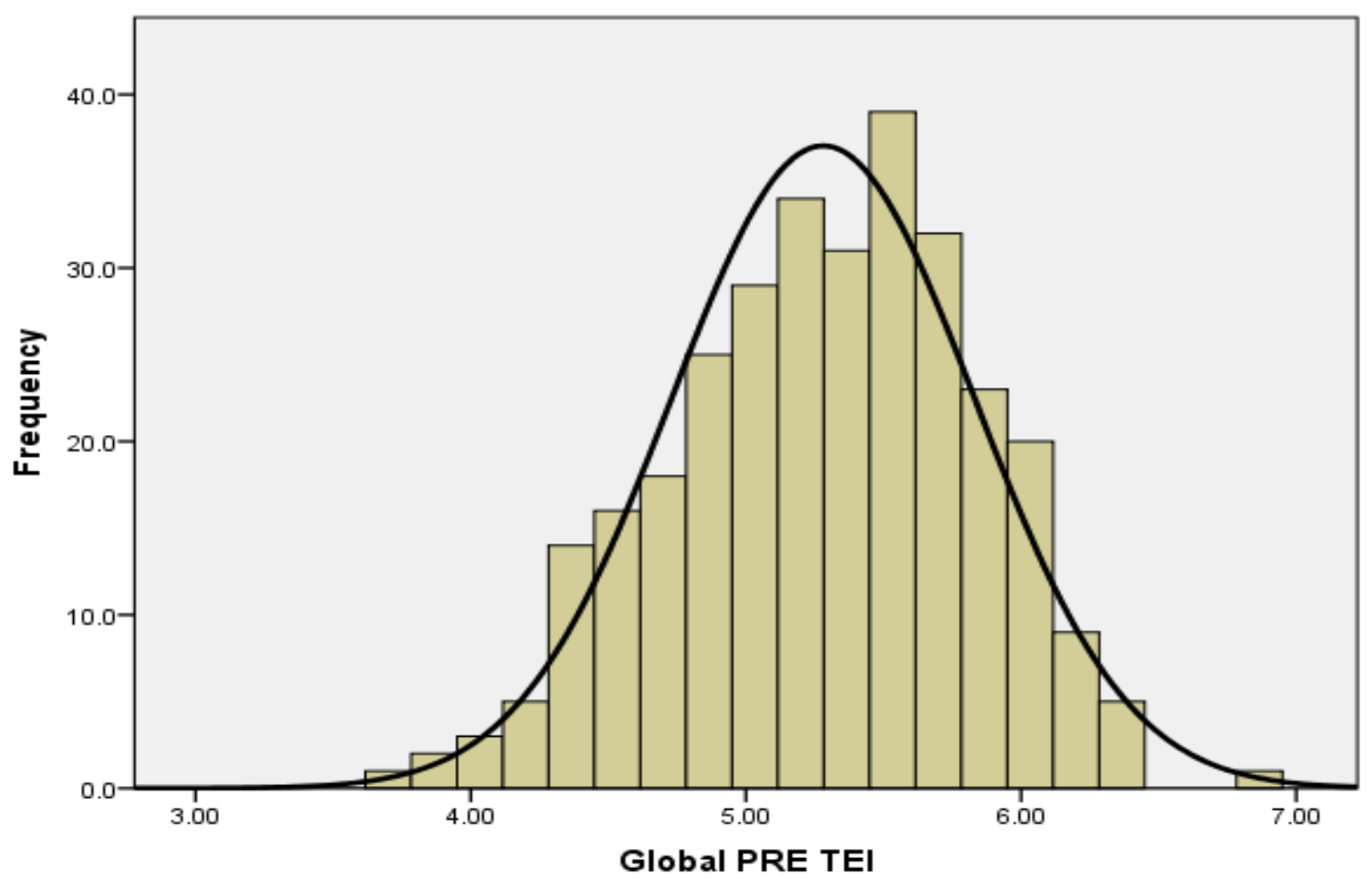

Figure. 3 - Pre TEI Score Distribution

Motive Domains - The motivational scale used originates from the work done by Driver (1983) and incorporates some of the Recreation Experience Preference (REP) scales that represent most of the domains. In essence, this work incorporates a variety of domains, scales and core statements, all structured to measure preference for recreational experiences or motivations. These scales were used to measure individual's motivation for participation in an Adventure West Virginia trip. In all, 21 domains encompass the REP. In this study, however, researchers selected domains that they considered most relevant to the Adventure WV experience. Sixteen of the overall domains were chosen to be a part of the study, with every scale represented within that domain. In all, 37 items were chosen, all measured using a 7 point Likert scale (1=Not Important to 7=Extremely Important) in the pre-test. 
Factor Analysis (Varimax rotation) was used to reduce the 37 items into motivation domains (Table 10). The items factored into 8 domains: Achievement and Stimulation (AS), Autonomy and Leadership (AL), Sharing Similar Values (SSV), Escaping Physical Stressors and Tension (EPST), Introspection (IS), Outdoor learning (OL), Independence and Risk Taking (IRT) and Meeting New People (MNP) All of the items had factor loading scores greater than 0.4. Fairly strong Cronbach's alpha scores for seven of the eight motive domains suggest the factors are reliable: .817(AS), .780 (AL), .812 (SSV), .821 (EPST), .854 (IS), .771 (OL) and .763 (IRT). A moderate Cronbach's alpha, .577, was reported for one factor (MNP). 
Table 10. Factor and Factor Loadings for Motivational Items

\begin{tabular}{|c|c|c|c|c|c|c|c|c|c|}
\hline Factors and Items & Introspection & $\begin{array}{l}\text { Escaping } \\
\text { Physical } \\
\text { Stressors } \\
\text { and Tension }\end{array}$ & $\begin{array}{l}\text { Achievement } \\
\text { and } \\
\text { Stimulation }\end{array}$ & $\begin{array}{l}\text { Sharing Similar } \\
\text { Values }\end{array}$ & $\begin{array}{l}\text { Autonomy } \\
\text { and } \\
\text { Leadership }\end{array}$ & $\begin{array}{l}\text { Outdoor } \\
\text { Learning }\end{array}$ & $\begin{array}{l}\text { Independence } \\
\text { and Risk Taking }\end{array}$ & $\begin{array}{l}\text { Meeting } \\
\text { New } \\
\text { People }\end{array}$ & $\begin{array}{l}\text { Cronbach's } \\
\text { Alpha }\end{array}$ \\
\hline Introspection & & & & & & & & & .854 \\
\hline To help get rid of some clutched up feelings & 680 & & & & & & & & \\
\hline To think about your personal values & 630 & & & & & & & & \\
\hline To have your mind move at a slower pace & 629 & & & & & & & & \\
\hline To experience tranquility & .604 & & & & & & & & \\
\hline To be near considerate people & .556 & & & & & & & & \\
\hline To develop personal, spiritual values & .481 & & & & & & & & \\
\hline Escaping Physical Stressors and Tension & & & & & & & & & .821 \\
\hline To get away from the clatter and racket back home & & .745 & & & & & & & \\
\hline To be away from crowds of people & & .735 & & & & & & & \\
\hline $\begin{array}{l}\text { To get away from the crowds of people } \\
\text { To have a change from your daily routine }\end{array}$ & & $\begin{array}{l}.699 \\
.544\end{array}$ & & & & & & & \\
\hline Achievement and Stimulation & & & & & & & & & .817 \\
\hline To have thrills & & & .740 & & & & & & \\
\hline To chance dangerous situations & & & .678 & & & & & & \\
\hline To experience new and different things & & & .661 & & & & & & \\
\hline To test your endurance & & & .635 & & & & & & \\
\hline To be with people who enjoy the same things I do & & & .537 & & & & & & \\
\hline To test your abilities & & & .530 & & & & & & \\
\hline Sharing Similar Values & & & & & & & & & .812 \\
\hline To be near others who could help & & & & 689 & & & & & \\
\hline To be with respectful people & & & & .596 & & & & & \\
\hline To teach your outdoor skills to others & & & & .546 & & & & & \\
\hline To have others think highly of you for participating & & & & .522 & & & & & \\
\hline To become better at a particular skill & & & & .484 & & & & & \\
\hline To tell others about the trip & & & & .422 & & & & & \\
\hline
\end{tabular}


Table 10. Factor and Factor Loadings for Motivational Items

\begin{tabular}{|c|c|c|c|c|c|c|c|c|c|}
\hline Factors and Items & Introspection & $\begin{array}{c}\text { Escaping } \\
\text { Physical } \\
\text { Stressors } \\
\text { and Tension }\end{array}$ & $\begin{array}{l}\text { Achievement } \\
\text { and } \\
\text { Stimulation }\end{array}$ & $\begin{array}{l}\text { Sharing Similar } \\
\quad \text { Values }\end{array}$ & $\begin{array}{l}\text { Autonomy } \\
\text { and } \\
\text { Leadership }\end{array}$ & $\begin{array}{l}\text { Outdoor } \\
\text { Learning }\end{array}$ & $\begin{array}{l}\text { Independence } \\
\text { and Risk Taking }\end{array}$ & $\begin{array}{l}\text { Meeting } \\
\text { New } \\
\text { People }\end{array}$ & $\begin{array}{l}\text { Cronbach's } \\
\text { Alpha }\end{array}$ \\
\hline Autonomy and Leadership & & & & & & & & & .780 \\
\hline To control things & & & & & .730 & & & & \\
\hline To help direct the activities of others & & & & & .647 & & & & \\
\hline To feel isolated & & & & & .616 & & & & \\
\hline To be my own boss & & & & & .557 & & & & \\
\hline To be with and observe other people using the area & & & & & .409 & & & & \\
\hline Outdoor Leadership & & & & & & & & & .771 \\
\hline To view the scenery & & & & & & .765 & & & \\
\hline To be closer to home & & & & & & .741 & & & \\
\hline To study nature & & & & & & .651 & & & \\
\hline To get to know the lay of the land & & & & & & .474 & & & \\
\hline Independence and Risk Taking & & & & & & & & & .763 \\
\hline To feel independence & & & & & & & .801 & & \\
\hline To gain a sense of self confidence & & & & & & & .772 & & \\
\hline To take risks & & & & & & & .488 & & \\
\hline Meeting New People & & & & & & & & & .577 \\
\hline To talk to new and varied people & & & & & & & & .725 & \\
\hline \multirow{2}{*}{$\begin{array}{l}\text { To be with members of your group } \\
\text { To develop your knowledge of the things here }\end{array}$} & & & & & & & & .684 & \\
\hline & & & & & & & & .660 & \\
\hline
\end{tabular}


TEI and Motivations- Analysis of Variance was used to examine if motivations are dependent on TEI tertile groups (Table 11). Two of the 8 domains (i.e., Achievement and Stimulation and Outdoor Leadership) were significantly dependent $(p<.05)$ on pre-test Global TEI scores. The high and medium Global TEI groups had stronger motivations to attain AS and OL. High and medium Global TEI groups also reported a stronger motivation to attain SSV, but it was only suggestive $(p<.10)$.

The top motivations for the low Global TEI group include Meeting New People (mean=4.94), Escaping Physical Stressors and Tension (mean=4.42), and Independence and Risk Taking (mean=4.39). The top motivations for the medium Global TEI group include Meeting New People (Mean=5.05), Achievement and Stimulation (mean=5.16), Escaping Physical Stressors and Tension (mean=4.49), and Independence and Risk Taking (mean=4.48). Finally, the top motivations for the high Global TEl group include Meeting New People (mean =5.20), Achievement and Stimulation (mean=5.23), Escaping Physical Stressors and Tension (mean=4.52), and Outdoor Leadership (mean=3.20). 
Table 11. TEl Segments and Motivational Domains ANOVA

\begin{tabular}{|c|c|c|c|c|c|}
\hline Motive Domains and TEI Segments & Mean & $d f$ & $\mathrm{~F}$ & Sig & Tukey's B \\
\hline \multicolumn{6}{|l|}{ Introspection } \\
\hline 3 & 3.60 & & & & \\
\hline 1 & 3.71 & 296 & 3.746 & 5.39 & \\
\hline 2 & 3.79 & & & & \\
\hline \multicolumn{6}{|c|}{ Escaping Physical Stressors and Tension } \\
\hline 1 & 4.42 & & & & \\
\hline 2 & 4.49 & 297 & 0.155 & .857 & \\
\hline 3 & 4.52 & & & & \\
\hline \multicolumn{6}{|l|}{ Achievement and Stimulation } \\
\hline 1 & 4.81 & & & & \\
\hline 2 & 5.16 & 297 & 4.925 & $.008 * *$ & $1>2>3$ \\
\hline 3 & 5.23 & & & & \\
\hline \multicolumn{6}{|l|}{ Sharing Similar Values } \\
\hline 1 & 3.84 & & & & \\
\hline 2 & 3.99 & 296 & 2.437 & .089 & \\
\hline 3 & 4.19 & & & & \\
\hline \multicolumn{6}{|l|}{ Autonomy and Leadership } \\
\hline 2 & 3.18 & & & & \\
\hline 3 & 3.20 & 300 & 0.302 & .739 & \\
\hline 1 & 3.30 & & & & \\
\hline \multicolumn{6}{|l|}{ Outdoor Leadership } \\
\hline 1 & 4.04 & & & & \\
\hline 3 & 4.40 & 295 & 3.746 & $.025 * *$ & $1>3>2$ \\
\hline 2 & 4.46 & & & & \\
\hline \multicolumn{6}{|l|}{ Independence and Risk Taking } \\
\hline 3 & 4.28 & & & & \\
\hline 1 & 4.39 & 295 & 0.719 & .488 & \\
\hline 2 & 4.48 & & & & \\
\hline \multicolumn{6}{|l|}{ Meeting New People } \\
\hline 1 & 4.94 & & & & \\
\hline 2 & 5.05 & 287 & 1.650 & .194 & \\
\hline 3 & 5.20 & & & & \\
\hline
\end{tabular}

*Paired t-test, two tailed $\mathrm{p} \leq .05-{ }^{* *}$ Paired t-test, two tailed $\mathrm{p} \leq .01$ 
TEls and Collegiate Preparation- This next section examines the association between Global TEI and collegiate preparation. Collegiate preparation was measured using a nominal (yes/no) variable.(Do you feel as if your trip has better prepared you for your transition into college?). There were no significant associations between Global TEI and preparation for college $\left(\chi^{2}=.589, \mathrm{df}=2, \mathrm{p}=.745\right)$. This finding suggests that AWV may be successful in preparing students regardless of their pre TEl scoring rank.

TEls and First Generation Students - Chi-square was used to examine the association between Global TEI and first generation students. Much like the collegiate preparation approach, this was measured with a nominal (yes/no). (Did either of your parents graduate from college?). There was a significant association between Global TEI and first generation students $\left(\chi^{2}=5.313, d f=2, p=.07\right)$. This result suggests that the lowest scoring TEl group had the highest percentage of first generational collegiate students. That is, first generation students are more likely to have lower TEI scores. Overall, 28 of the $101(28 \%)$ lowest scoring individuals were also first generational students. In comparison, only 14 out of 97 (14\%) of the medium scoring group and 22 out of 108 (20\%) of the high scoring group were first generational students. As a side note, there was no significant association between students who responded as having parents who attended WVU and their Global TEI $\left(\chi^{2}=6.319, \mathrm{df}=2, \mathrm{p}=.177\right)$.

In State vs. Out of State and TEI Group - - A Chi-square analysis was used to examine the association between place of residence (in-state or out of state) and Global TEl. There was no significant association between the two variables $\left(\chi^{2}=2.498, d f=2, p=.287\right)$. That is, pre-trip Global TEI scores are not dependent on state residency. 
Ethnicity and TEI Group-The association between ethnicity and Global TEI was

examined using Chi-square analysis. The result was not significant $\left(\chi^{2}=3.923, d f=8, p=.864\right)$, however; it is important to note the lack of responses for categories other than White. That is, the majority of respondents identified themselves as White.

Extracurricular/Service Learning Activities and TEI Group - Chi-square analysis was used to examine the association between extracurricular/service learning activities and Global TEI. Extracurricular activities and service learning activities were both categorical variables. (While in high school, did you participate in any class-related service learning activities?, While in high school, did you participate in extracurricular activities-i.e. athletics, student council/government, marching band, co-op, FFA, FBLA, etc.?). No significant evidence was found supporting an association between Global TEI and extracurricular activities $\left(\chi^{2}=2.203\right.$, $d f=2, p=.332)$ and Global TEl and service learning activities. $\left(\chi^{2}=.014, d f=2, p=.993\right)$. These finding suggest that, regardless of the teritle segmentation, students are participating in activities outside of school in a similar fashion.

Trip Type and TEI Group - To help determine if any correlation existed within the trip selected and TEI group identified, a cross tabulation of each group was conducted. No significant association was found $\left(\chi^{2}=3.911, d f=6, p=.689\right)$ between the identified TEl groupings and the selected trip type.

Trip Satisfaction and TEI Group - Trip satisfaction recorded via a Likert style type question (1=Not at all Satisfied, 2= Slightly Satisfied, 3=Moderately Satisfied, 4=Very Satisfied, $5=$ Extremely Satisfied). This question was located within the post-test survey manual (How 
satisfied are you with the trip you just participated in?). Through an ANOVA, high statistical evidence ( $p \leq .001)$ was found supporting the notion that the lowest scoring TEl group was the least satisfied of all the TEl segmentations. Table 12 outlines the ANOVA associated with trip satisfaction.

Table 12. Trip Satisfaction and TEI

\begin{tabular}{lccccc}
\hline TEl Segmentation & Mean & df & $F$ & Sig (2-tailed) & Tukey's B \\
\hline 1 (Low TEI) & 4.34 & 305 & 6.933 & $.001 * *$ & $1>2,3$ \\
2 (Medium TEI) & 4.57 & & & & \\
3 (High TEI) & 4.66 & & & \\
\hline \multicolumn{5}{c}{ *Paired t-test, two tailed $\mathrm{p} \leq .05$ - **Paired t-test, two tailed $\mathrm{p} \leq .01$}
\end{tabular}

TEl Segments, Factor Gains and Global TEI- In comparing the TEl segments, TEI factors and global scores, significant finding were identified, detailing the development of students within AWV. All four of the TEl factors, along with the Global score, were used in this analysis. The gains associated with the TEl segments were predictable, with the lowest TEl group gaining significantly more $(\alpha=.05)$ in Well Being. Significance $(\alpha=.05)$ was found in the factor specified above, with Well Being $(F=6.841, p$-value $=.001)$ proving to have the most significant change. 
Table 13. TEI Segments and TEI Factors ANOVA

\begin{tabular}{|c|c|c|c|c|c|}
\hline TEI Factors and TEI Segments & Mean & $d f$ & $\mathrm{~F}$ & Sig & Tukey's B \\
\hline \multicolumn{6}{|l|}{ Well Being } \\
\hline 3 & .175 & & & & \\
\hline 2 & .328 & 302 & 6.841 & $.001 * *$ & $3>2>1$ \\
\hline 1 & .485 & & & & \\
\hline \multicolumn{6}{|l|}{ Self-Control } \\
\hline 2 & .162 & & & & \\
\hline 3 & .165 & 306 & 0.441 & .644 & \\
\hline 1 & .247 & & & & \\
\hline \multicolumn{6}{|l|}{ Emotionality } \\
\hline 3 & .141 & & & & \\
\hline 1 & .293 & 303 & 2.512 & .083 & \\
\hline 2 & .333 & & & & \\
\hline \multicolumn{6}{|l|}{ Sociability } \\
\hline 3 & .114 & & & & \\
\hline 1 & .227 & 304 & 2.197 & .113 & \\
\hline 2 & .320 & & & & \\
\hline \multicolumn{6}{|l|}{ Global TEI } \\
\hline 3 & .152 & & & & \\
\hline 2 & .281 & 296 & 2.698 & .069 & \\
\hline 1 & .285 & & & & \\
\hline
\end{tabular}

Student Typology - Overall, very few variables were dependent on the TEI group and included in the student typology. Located below (Table 13) is a recap of the significant items found. In all, the low rated TEI group was found to have the lowest motivation, as compared to the other groups, accounting for the highest proportion of low motivational items measured. The low rated TEI group also had the lowest trip satisfaction out of the three classified TEI scores and the highest proportion of first generational students. The medium TEI group members were least likely to be first generational students. The TEl factor gains indicated that the lowest TEI group benefited the most from AWV. 
Table 14. Student Typology

\begin{tabular}{lccc}
\hline & Low TEI & Medium TEI & High TEI \\
\hline $\begin{array}{l}\text { Motivations } \\
\text { High }\end{array}$ & AS, SSV, OL & OL & AS,SSV \\
Low & & -- & --- \\
& High & Very High & Very High \\
Trip Satisfaction & Moderately Low & Very Low & Low \\
First Generational Students & & & \\
& & & \\
TEI Factor Gain & High & Medium & Low \\
Well Being & --- & --- & -- \\
Self-Control & --- & --- & -- \\
Emotionality & --- & --- & -- \\
Sociability & --- & - & \\
Global TEI & & & \\
\hline
\end{tabular}

Note: Achievement and Stimulation (AS), Autonomy and Leadership (AL), Sharing Similar Values (SSV), Escaping Physical Stressors and Tension (EPST), Introspection (IS), Outdoor learning (OL), Independence and Risk Taking (IRT) and Meeting New People (MNP) 


\section{Research Question 3 - What specific trips contribute most to AWV students' TEI gain scores?}

Impacts on Measured TEI

The following results in this section help outline the elicited impacts associated with the selfreported TEI scores. Specific analyses were used to compare TEI by the type of AWV trip

Trip Type and TEI- In all, three specific areas were significantly impacted through participation, with two factors and global TEI receiving the highest variability in the mean difference when trip type was considered. This variability in means was highly significant $(\alpha=.05)$. Sociability $(F=4.605, p=.004)$ and self-control $(F=3.249, p=.017)$ proved to obtain the highest variability in relation to the type of impact received. Global TEI $(p=.007)$ also displayed a high probability of being impacted by the type of trip chosen through AWV.

Some common themes were identified in the results. In every significant instance, Wilderness actually lowed TEI and its subsequent factors in many cases. As an example, the mean gain score of self-control actually lowered $(M G=-.1344)$ in comparison to the other AWV trips. All of the TEl factor and global mean gain score comparisons are provided in Table14 where compared by trip type. 
Table 15. ANOVA of TEI Factor and Global TEI Mean Gain (MG) scores for Four Adventure WV Trips

\begin{tabular}{|c|c|c|c|c|c|}
\hline & $\mathrm{N}$ & MG for Trip & df & $\mathrm{F}$ & Sig \\
\hline Self-Control & & & 316 & 3.429 & $.017^{* *}$ \\
\hline Explore & 117 & .192 & & & \\
\hline Odyssey & 131 & .238 & & & \\
\hline Habitat & 38 & .421 & & & \\
\hline Wilderness & 31 & -.134 & & & \\
\hline Emotionality & & & 311 & 0.889 & .442 \\
\hline Explore & 117 & .258 & & & \\
\hline Odyssey & 128 & .286 & & & \\
\hline Habitat & 36 & .347 & & & \\
\hline Wilderness & 31 & .100 & & & \\
\hline Well-Being & & & 307 & 2.015 & .112 \\
\hline Explore & 112 & .397 & & & \\
\hline Odyssey & 128 & .348 & & & \\
\hline Habitat & 37 & .373 & & & \\
\hline Wilderness & 31 & .070 & & & \\
\hline Sociability & & & 313 & 4.605 & $.004^{* *}$ \\
\hline Explore & 117 & .238 & & & \\
\hline Odyssey & 129 & .302 & & & \\
\hline Habitat & 37 & .207 & & & \\
\hline Wilderness & 31 & -.215 & & & \\
\hline Global TEI & & & 296 & 4.124 & $.007^{* *}$ \\
\hline Explore & 111 & .240 & & & \\
\hline Odyssey & 122 & .284 & & & \\
\hline Habitat & 34 & .299 & & & \\
\hline Wilderness & 30 & -.035 & & & \\
\hline
\end{tabular}


Low TEI, Trip Type and Impact - The TEI mean gain scores were compared among the tertile segmentations (Low TEI, Medium TEI and High TEI). As shown above, the impacts identified in this analysis augmented the fact that Wilderness was a weaker performer in comparison to the other AWV trips offered.

Although two areas were found to be of significant difference $(\alpha=.05$, Sociability $=.015$ and Global TEI=.016), all factors were shown to either decrease or have no gain when both the Low TEI group and Wilderness were paired. 
Table 16. ANOVA of TEI Factor and Global TEI Mean Gain (MG) scores for Four Adventure Trips with Low TEl Segmentation

\begin{tabular}{|c|c|c|c|c|c|}
\hline & $\mathrm{N}$ & MD for Trip & df & $\mathrm{F}$ & Sig (2-tailed) \\
\hline Self-Control & & & 100 & 1.562 & .230 \\
\hline Explore & 35 & .305 & & & \\
\hline Odyssey & 40 & .271 & & & \\
\hline Habitat & 16 & .385 & & & \\
\hline Wilderness & 10 & -.267 & & & \\
\hline Emotionality & & & 98 & 1.219 & .307 \\
\hline Explore & 35 & .258 & & & \\
\hline Odyssey & 38 & .286 & & & \\
\hline Habitat & 16 & .347 & & & \\
\hline Wilderness & 10 & -.013 & & & \\
\hline Well-Being & & & 98 & 1.709 & .170 \\
\hline Explore & 33 & .520 & & & \\
\hline Odyssey & 40 & .592 & & & \\
\hline Habitat & 16 & .448 & & & \\
\hline Wilderness & 10 & .000 & & & \\
\hline Sociability & & & 99 & 3.665 & $.015^{* * *}$ \\
\hline Explore & 35 & .457 & & & \\
\hline Odyssey & 39 & .222 & & & \\
\hline Habitat & 16 & .104 & & & \\
\hline Wilderness & 10 & -.367 & & & \\
\hline Global TEI & & & 95 & 3.645 & $.016 * * *$ \\
\hline Explore & 33 & .323 & & & \\
\hline Odyssey & 37 & .366 & & & \\
\hline Habitat & 16 & .304 & & & \\
\hline Wilderness & 10 & -.177 & & & \\
\hline
\end{tabular}

*Paired t-test, two tailed $\mathrm{p} \leq .05-{ }^{* *}$ Paired t-test, two tailed $\mathrm{p} \leq .01$

Medium TEl, High TEI, Trip Type and Impact -No significant difference $(\alpha=.05)$ was found in relation to the differences accounted for. Although Wilderness performed worse in relation to all other programs, this performance was not significantly different when compared to the other programs. Table 16 outlines the findings associated with TEI and AWV. 
Table 17. ANOVA of TEI Factor and Global TEI Mean Gain (MG) scores for Four Adventure Trips with Medium and High TEI Segmentation

\begin{tabular}{|c|c|c|c|c|c|}
\hline & $N$ & MD for Trip & $d f$ & $F$ & Sig (2-tailed) \\
\hline Self-Control & & & 205 & 1.538 & .206 \\
\hline Explore & 79 & .144 & & & \\
\hline Odyssey & 89 & .208 & & & \\
\hline Habitat & 18 & .333 & & & \\
\hline Wilderness & 20 & -.108 & & & \\
\hline Emotionality & & & 204 & 0.568 & .637 \\
\hline Explore & 79 & .223 & & & \\
\hline Odyssey & 88 & .233 & & & \\
\hline Habitat & 18 & .403 & & & \\
\hline Wilderness & 20 & .119 & & & \\
\hline Well-Being & & & 203 & 0.925 & .430 \\
\hline Explore & 79 & .279 & & & \\
\hline Odyssey & 87 & .236 & & & \\
\hline Habitat & 18 & .343 & & & \\
\hline Wilderness & 20 & .092 & & & \\
\hline Sociability & & & 204 & 1.979 & .118 \\
\hline Explore & 79 & .144 & & & \\
\hline Odyssey & 88 & .324 & & & \\
\hline Habitat & 18 & .241 & & & \\
\hline Wilderness & 20 & -.042 & & & \\
\hline Global TEI & & & 200 & 1.385 & .249 \\
\hline Explore & 78 & .204 & & & \\
\hline Odyssey & 85 & .248 & & & \\
\hline Habitat & 18 & .294 & & & \\
\hline Wilderness & 20 & .035 & & & \\
\hline
\end{tabular}




\section{Discussion}

The research findings presented in the previous section are discussed here, and program recommendations will be provided in light of study findings. Finally, comments will be given to improve future research and to provide new avenues for the continuation of research in both the fields of El and outdoor orientation.

The purpose of this quasi-experimental study included three broad areas. First, analyses were conducted to help solidify the understanding as to whether outdoor pre-orientation programs (i.e. AWV) help students obtain higher levels of perceived TEI upon completion of the program. Second, a study typology was constructed, deriving multiple variables such as trip type, socioeconomics and motivations. Finally, the specific AWV trips were compared to see which contributed most to TEI and the students who were apart of AWV. In all, these research questions give the breadth of focus needed to help structure this section, providing the materials needed to give insight into the results found.

\section{Research Question \#1}

Does an outdoor based pre-orientation program help students obtain higher levels of perceived trait El upon completion of the program?

In using the TEI-SF, strong evidence was found supporting the notion that higher levels of perceived TEI can be derived upon completing the AWV program. In using a two-tailed paired t-test, the multiple variables and factors associated with the construct were tested via pre and post test scores. Line item questions and factor items located within the construct were found 
to be of high significance ( $\alpha=.001$ ). These four factors, as mentioned above, are the higher order combinations of the line item questions mentioned earlier. Finally, Global TEI was also found to be significantly altered through participation $(\alpha=.001)$, indicating the entire construct of TEl benefited as well.

These increases indicate that AWV was influential in sustaining gains in TEI. Through the use of a custom based curriculum approach, entitled Leave a Trace, where University 101 objectives are integrated throughout outdoor, challenge course based and service learning activities (See Grout, 2009), students are engaged in discussions led by upperclassmen concerning programs, resources and organizations that are available to them. This integration, along with the social nature of AWV, situates students to actively process their thoughts and abilities concerning the transitional issues surroundings college. This is an atmosphere where students openly engage in discussions concerning fears and apprehensions held toward leaving home. Leaders facilitate these discussions to help students gain a better understanding of the norms held within college, constructing a viewpoint that eases each student into the transitional difficulties they will encounter.

Through these measures, however, it can be derived that the gains associated with TEI were promoted through the curricular structure AWV promotes. Although not intended to be an intervention program specifically aimed at TEI, AWV does facilitate many of the items located within the construct, allowing students to become more self-aware of their abilities. Examples of this association can be found within the line item questions and the curriculum covered through AWV. Core items such as stress, motivations, intrapersonal interactions, 
healthy decisions and adaption are all covered either peripherally or directly with AWV. In covering these items, students are directly exposed to discussions that help facilitate many of the questions found within the TEIQ-SF (I can deal effectively with people, On the whole, I'm able to deal with stress, I normally find it difficult to keep myself motivated, Generally, I'm able to adapt to new environments). Subsequent talks with other students or leaders many also facilitate growth with TEl, with knowledge gained through the exchange of ideas. The openness cultivated through these activities is also supported through the journaling exercises required for every student. These exercises prompt students to reflect upon the activities completed throughout the day, structuring their thought process to make connections regarding college. These activities allow students to engage in an open dialogue with themselves concerning their perceptions of college. This reflection prompts the activation for students to scaffold the ideas learned through AWV, creating new connections with self-awareness and their abilities.

All this, however, is supported directly through the experiential mindset AWV promotes. In taking the experiential learning cycle developed by Kolb (1984), AWV allows students to participate in recreational activities laden within a establish curriculum. This sees students participating in activities (i.e. rock climbing) where they reflect immediately after the experience. Leaders then facilitate a discussion based upon these reflections, garnering the connections needed in order to develop meaning. These connections often see elements of the activity portrayed as metaphors for an abstract conceptualization (i.e. college). This is then followed by additional activities or journaling, allowing students to follow-up on the new ideas received. This scaffolding of ideas permits students to develop their skills and perceptions, 
gaining experience in order to apply their new found knowledge. Even though this current study did not explore the relations associated with reflection and TEI development, the structural elements of outdoor orientation, journaling and development are cited within the literature. Bell (in press) and Bell and Holmes (2011) give insight into the benefits associated with the reflective state AWV provides, depicting the development students encounter as a result. These findings, although not truly associated through study design or intentional output, give credence to the fact that active journaling and reflection help foster an understanding that facilitates growth within students.

Although this approach has not necessarily had classical ties to the TEI construct, gains associated with self-efficacy have been made (Grout, 2009). With TEl having the alternative name of 'emotional self-efficacy', connections with the two constructs can and should be considered. Although Grout (2009) specifically relied on challenge course based activities, the curriculum applied is of direct application to this study. This would suggest a similar transference of perceptions, with AWV promoting gains of TEI through participation.

These increases are also associated with the findings of Qualter et al. (2007), supporting the notion that through an intervention program (AWV), EI can be raised. These elicited changes are important, as noted earlier by Qualter et al. (n.d.), Qualter et al. (2009), Hogan (2006), Petrides et al. (2006) and Petrides et al. (2004) suggesting El and TEI assist with transitional and social concerns for students. 


\section{Research Question \#2}

Can a study typology be derived from variables such as trip type, socioeconomics and motivations?

A student typology was successfully created from our analysis. To help complete this task, tertile segmentations were identified to help understand the diversity of students. Pretest TEI-SF scores were used to create the three segments: low (3.65-5.04), medium (5.06-5.52) and high (5.53-7.00) TEI (see Table 14). Motivational factors (constructed through principle component factor analysis, with Varimax rotation) and additional socioeconomic information collected via both the pre and post-test instruments were also considered when developing the typology. All of the analyses were used to identify and describe three distinct student typologies.

Overall, even with multiple variables examined, only limited items were significantly dependent on are associated with the TEI groups. Nevertheless, these variables collectively help define a typology of students that participate in the AWV program. This also assists in the potential to better understand the type of student who many embody the TEI segmentation completed. In all, through the use of pre-TEI scores, students were grouped accordingly to understand the profile that exists within trips. With identifiable segments now created, sophisticated models of application can be applied to better facilitate activities suited for each TEl segment. This approach could essentially include marketing and curricular design, with AWV promoting selected trips designed for each independent group. This understanding of group 
division will allow for 'market segmentation' to occur, allowing AWV, and other programs like it, to better recruit and facilitate activities for the groups identified.

This segmentation also allows for the continuation of understanding regarding the TEI construct. With the meshing of outdoor orientation and TEI commenced within the study, this profile will assist with the understanding of how certain individuals react toward programming. By understanding that all segments have identifiable aspects that make them unique, this typology will assist in the continuation of the individual TEI profile, specifically related to outdoor orientation. With variables shown to be significantly linked to specific segments, an understanding of what could potentially link TEI scores to motivations and reactions can now begin to be mediated. Although this study did not specifically address this issue above, a beginning profile has been created to help understand how students react accordingly. With demographic date supporting the creation and understanding of the profile, a understanding of what constitutes a 'low' TEI can be understood. This is couple along with can be done to assist this student, specifically in relation to their self-perceived TEl score.

High TEI Students - This segment of the student typology grouped the high scoring TEI students going through the AWV program. In all, the motivational items found to be significant where sharing similar values and achievement and stimulation. The trip satisfaction for this segment was very high and the number of first generational students in comparison to the other segments was medium.

In relating this information to practical use, however, it must be noted that these students are often the highest performing individuals, both in terms of social and academic 
performance (Petrides et al, 2006 \& Petrides et al., 2004). Their motivational aspects indicate that social achievement and stimulation are high priorities, as opposed to independence and introspection, which would lead to make practical sense due to their high scoring pre TEI scores. Although not significant, this indication is mediated through the motivational scores found in relation to the other TEI segments. Along with SSV and AS, MNP and EPST were also rated high. IS and IRT were the low rated motivational factors associated with this TEI segment.

The high satisfaction related to participation also relates well to their initial scores, as the social nature of AWV initiates an atmosphere conducive to their motivational approach. In all, these students are a relative given for AWV, with both their motivational approach and satisfaction for programming leading well into how AWV is facilitated for students. Attracting these participants should be considered a priority, however, as they not only fit well into the structural applications of the program, but also help facilitate the social foundations that help AWV with its facilitation of knowledge and experience. Their dispositions may help mediate the other students located throughout AWV, as they are structurally sound within the socially and emotionally laden structures found within the program.

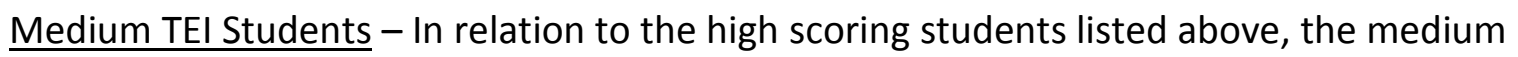
scoring students were placed within the middle of the TEI distribution of scores. The motivational items found to be related to this segment are independence and risk taking, outdoor learning and introspection, as opposed to autonomy and leadership. Trip satisfaction was moderate in comparison to the other groups and the number of first generational students was lowest in comparison as well. 
In structuring the identify of this group, it can be inferred through their motivational preferences that the medium TEI group prefers more independent activities integrated through an outdoor setting. By having a lower motivational score related with autonomy and leadership, this group seems to be orientated within interpersonal items, most likely selfdiscovery or self-reflection. This is in contrast to the higher level TEI group, where social interactions within the group were proven to be of high motivational interest. Nevertheless, this medium segmentation yet again plays well into the structure of AWV and its subsequent programming, due to the amount of internal self-reflection needed in order to complete the class. In all, journaling, solo experiences and goal lettering incorporate the approach utilized throughout AWV, situating well for these students and their preferences. The satisfaction levels associated with this group may be a result of the interpersonal interactions needed and promoted through participation. With motivational influences situated within the introspection of individual needs, the social requirements of camping and participating may push these students outside their created comfort zone. This push

Low TEI Students - This segment within the TEI distribution consisted of the the lowest scoring students being accumulated and grouped. The motivational items for this group proved to be lower in number in comparison to the other segments, with only one item (autonomy and leadership) being rated highest among the others. Five other motivational items (escaping physical stressors and reducing tension, achievement and stimulation, sharing similar values, outdoor learning and meeting new people) were found to be lowest when compared to the two previous TEI segments. This low motivational structure proves to be a logical inference, as the 
lowest rated group would be assumed to have the lowest motivation in terms of participation. Trip satisfaction was also lowest and the number of first generational students was highest. These students also obtained the most in average with Global TEl scores.

These variables help give insight into the type of student found to score lowest in relation to this study, with low TEl scores relating closely to low motivation, satisfaction and exposure to collegiate knowledge. These students would most likely find it difficult to find the appropriate means necessary to help express their motivational interests within the structure of AWV, with the social and introspective elements laden throughout the program. These difficulties help explain the lack of satisfaction found within this segment, although still high, as AWV was least likely to provide a satisfactory experience for this group. This low satisfaction, however, does not necessarily correlate directly to the types of gains inferred through participation. With low TEl scores, this group stood to gain the most through participation, even though their motivational preferences may have not been met. With that said, AWV may have situated these students in situations where they were required to go outside their preferred comfort level, requiring them to participate in activities they have yet been prepared for (depending on their TEl level).

Having these students, nonetheless, may prove to be most important for the AWV program, with their success demonstrating the impact associated with the trips given. Marketing to these students could be accomplished by offering autonomous activities, where students are given leadership opportunities. This marketing would subsequently help recruitment, resulting in a higher number of lower scoring TEl individuals that participate. This 
increased recruitment is supported through Pascarella and Terenzini (1991), as they suggest students are faced with a multitude of dynamic variables as they begin college. These dynamic variables have proven to be mediated through outdoor orientation programs (Grout, 2009, Bell, 2006 \& Gass, 2003), however, allowing students to become better prepared for college. With all this said, and the findings of Qualter et al. (n.d.), Qualter et al. (2009), Hogan (2006), Petrides et al. (2006) and Petrides et al. (2004) supporting the application of El, it can be implied that through the participation of AWV, lower scoring TEI students stand to gain the most with participation and their transition to college, mediating an avenue for success that will permeate throughout their collegiate career.

\section{Research Question \#3}

What specific trip contributes most to TEI and the students who are apart of AWV?

With the student typology paving way to help further the knowledge associated with AWV and TEI, this research question primarily focuses on which trip impacts TEI most. In all, each specific trip associated with AWV was associated with the factors related to TEI. This association was done in accordance to gauge the impacts each trip had upon TEl and which trip faired best in relation to the student typology that was created.

AWV Groups and TEI Gains - When comparing the different types, it was obvious to see a district pattern in how the TEI factors changed throughout participation. For the most part, Explore, Odyssey and Habitat fared well in how they elicited gains in TEl. Within the broad approach taken in the initial ANOVA, it was found that these three programs assisted students 
with higher TEI scores within the posttest analysis. These gains were expected for AWV and the MGs for these programs are a positive sign for the activities done and the curriculum presented.

These findings are of great importance to the AWV program, as they yet again support the notion that the program works. As elaborated above, curriculum delivery may have had a hand in prompting these developments, as the integration of core objectives and experiential theory have shown to elicit positive results. A further notion, however, is that the activities presented may have also assisted in how the students reacted. With a variety of activities presented (see pg. 50), it can be inferred that the recreational and service learning activities presented through AWV assist in the overall development in TEI. This again can be credited to the experiential learning structure laden within AWV, as the benefits of scaffolding metaphorical ideas has shown to be of great value (See Discussion Question 1).

These findings, however, go beyond the application of simply understanding that AWV works, as the segmentation of students help offer an understanding of who the programs helps the most. In all, it must be understood that the three programs listed above cross the segmentation lines presented in the tertile separation. It was shown that through participation, all students were able to gain some sort of improved understanding, facilitating a raised notion concerning their perceived TEI score. This cross-boundary finding depicts AWV as a program that not only assists the students who are in most need, but also the students who are more suited to persist while in college. This as a whole situates AWV as a program that not only 
benefits certain students, but as a program that connects the entire spectrum of students to higher perceived abilities, promoting an ability to persist their collegiate career.

Continued program development should be pursued within the results found, however, as the application of raised TEI can have significant effects. As an example, institutional support can be garnered through the understanding that AWV promotes growth, especially within the construct of TEI. With evidence supporting the notion that AWV enhances the abilities for students to persist, the continued development of the program can be matched along the desired goals of the governing institution. With enhanced rates of persistence, in the form on retention, $A W V$ can gain institutional support for the programs offered and instructional style presented.

Wilderness and TEI - Nevertheless, it was must be noted that one particular trip, Wilderness, actually lowered self-perceived TEl scores in two TEl factors (Self-Control and Sociability) all while lowering Global TEl as well. This lowering is important to note not only due to the fact that it is the only program to have this elicited effect, but that the lowering potentially has impacts detrimental to student development (Qualter et al. (n.d.); Qualter et al., 2009, Hogan, 2006; Petrides et al., 2006 \& Petrides et al., 2004). In all, Wilderness, either through its structure or program facilitation, impeded development for students as they participated within the AWV program.

This negative elicited impact was experienced most within the lowest TEI segmented group, as it received the high proportion of negative reactions compared to the other higher scoring TEl groups. This negative association with Wilderness and the lowest TEl group warrants 
concern due to the fact that this TEI at-risk segment needs the most attention to help facilitate growth for the transitional issues related to college. Wilderness impeded this growth, essentially restricting the progress students stood to gain by participating in other programs associated with AWV. Both Sociability and Global TEI drifted negatively with Wilderness, as some aspect of programming limited the application of positive gains in elicited TEI development.

Although no specific question specified as to what element promoted the negative responses with $\mathrm{TEI}$, the structure of Wilderness may give insight into the potential scores found from this analysis. With smaller group sizes and specialized activities, Wilderness is often the least dynamic program when related to outdoor recreational activities. The length of programming also changes the dynamics associated with TEI and its impediment, with Wilderness having the lowest number of facilitation days. This limited number of days condenses time contact with student leaders and participants as well as number of classes offered throughout the programming cycle. This rigidity associated with programming and participation may have influenced the negative responses from Wilderness participants. Other variables that may have influenced the phenomena are the actual activities offered through Wilderness. Given backcountry living and hiking are the two primary activities; TEI may have suffered through the lack of dynamic and socially laden activities offered through the other programs within AWV.

These ideas, coupled with the findings presented earlier, may help in the continued development of the program, however, situating it with the sister programs offered through 
AWV. In all, with Wilderness eliciting a negative response, a closer look at programming is needed. By understanding that the program is the least dynamic and shortest facilitated, changes may be needed in order to help foster an environment that is beneficial to the development of TEI. By understanding that the three previous programs (Explore, Odyssey and Habitat) all assisted in the development of TEI, elements of programming should be considered as applicable and situated within the Wilderness framework. Although a major overhaul may not be necessary, further analyses and research should be done to better understand the essential elements that help assist TEI development within the trips mentioned. By understanding these elements, the transference of ideas can commence, situating Wilderness to be a strong program in relation to TEI and its ability to elicit a positive response.

A second avenue to assist programing, outside the notion of revamping activities, is to monitor and facilitate an understanding of when students sign up. With the freelance nature AWV provides students, any participant can self-select their program on a first come, first service basis. This approach allows for any participate to choose their program, under the assumption that the program is still available. With limited spots regulating the number of students participating, the more popular programs will evidently fill at a faster rate. These phenomena, as related to AWV, may have credence in the findings that have been associated with the Wilderness program. Understanding if students are actually self-selecting the program and not subsequently resorting to it as a last resort may assist in the understanding of why students are least likely to receive a TEI gain. Without the ability to actually choose the program they actually want, late students may be left with only Wilderness, rendering them a program 
they did not intended to choose. This limited selection may have ultimately left Wilderness with a proportion of students not fully understanding the structure of the program, limiting the effects of programming for each given student. By limiting the availability of self-selection, AWV may have subsequently lowered Wildernesses ability to impact TEI in a positive light, with only a small proportion of students actually wanting to be there. This is also coupled with the idea that many students may have had parents select their trip and a lack of understanding of the activities presented within the Wilderness framework.

With all this said, however, it must be suggested that the lowering of TEI may have resulted in a more profound accordance, one that actually sees the negative results in a more positive light. In taking the work corresponded by Hobbs (2005), where he focuses on the development of self-authorship in college students, the negative reactions related to Wilderness may have actually been of development for students, allowing them to self-reflect in a unparalleled notion. In all, when combining the idea of self-authorship, which is essentially the ability of any individual to actively create or invent their own beliefs, values, sense of self and relationships with others (Hobbs, 2005), Wilderness may have actually facilitated participants in a higher order manner unmatched by the other programs. With solitude being a rather large experience variable implemented within the Wilderness framework, students are often provoked to reflect individually on the trip, college and how the two are working together. This scaffolding of ideas is not one foreign to AWV, but one that is facilitated in a much different environment as related to Wilderness. With the combination of wilderness style living and mentality driving the tone many students encounter, the reflective process induced 
may have elicited a different response for the individuals participating. This response, although negative in nature, may have been one more related to self-authorship, allowing students to take grasp on their perceptions of self and TEI. This deeper perception of self also could have dismissed the influence of a socially desirable response (SDR), allowing the students to be more honest and open with their self-beliefs and identity.

It must be noted, however, along with the idea of self-authorship, that gains in TEI still assist individuals to be more persistent and prevalent, promoting the mediation of emotional regulation in a successful manner (Qualter et al., n.d.; Qualter et al., 2009; Hogan, 2006;

Petrides et al., 2006 and Petrides et al., 2004). Although individuals may have been more apt to grasp their own thoughts or values upon completion of the program, the negative reactions to TEI are of warrant. With TEI situated as a mediating variable, however, it must not be noted that some aspect of the Wilderness program elicited negative responses. By taking this, and the other findings present within this study, perhaps more can be learned about TEI and outdoor orientation regarding their mixture of approaches. 


\section{Future Research}

This study examined the TEI construct as it applies to outdoor orientation programs. In all, it was found that, through participation, students reported significant gains in TEl. Nevertheless, more research is needed to fully understand the variables associated with both TEI and outdoor orientation programming.

One suggestion for future research is to add a longitudinal approach in research design. With TEl having implications is assisting students with their academic and social encounters, having a study to monitor their participation in an outdoor orientation program would assist in developing a sophisticated understanding of longitudinal effects. This would aid in the understanding as to whether outdoor orientation produces gains outside of initial programming. This could also be paired with the student typology created, allowing for specific tracking. Future research could explore the persistence of the TEI construct within the segmented groups. This will also assist in the understanding if TEI gains can be supported throughout a specific duration of time (i.e. semester long).

In continuing research, especially in regards to the type of trips and their elicited impacts on TEI, more specific questioning is needed to determine the program elements that contribute to gains in self-reported TEI. Having a better understanding as to what programmatic elements implement the most change with students will assist with programming and foster a more complete understanding as to what provokes the greatest impacts for students. Knowing what provides the avenues needed to create and foster positive gains, TEl or not, will be a step toward a better understanding of outdoor orientation and facilitation. 
Finally, studies comparing the multiple methods for orientation programing are suggested. With a wide array of orientation programming available (classroom vs. outdoor), more research is needed to create an understanding of what program works best. With TEI mediating persistence with emotional regulation, comparing the multiple methods used with orientation may prove to be insightful. These results could be used for both the advancement of the construct and the approach needed for student retention. Additional support could be garnered for outdoor orientation as well, supporting the effectiveness of such programs. 


\section{References}

1. Abraham, A. (2006). The Need for the Integration of Emotional Intelligence Skills. http://ro.uow.edu.au/commpapers/238

2. Adventure West Virginia (2010). Program Choices. Retrieved June 20, 2010, from http://adventurewv.wvu.edu/programs

3. Association of Experiential Education (2007). What is Experiential Education? Retrieved February 10, 2010, from http://www.aee.org/about/whatlsEE

4. Austin, M. L., Martin, B., Mittelstaedt, R., Schanning, K., \& Ogle, D. (2009). Outdoor Orientation Program Effects: Sense of Place and Social Benefits. Journal of Experiential Education, 31(3), 435-439. Retrieved from EBSCOhost.

5. Baker, R. W., \& Siryk, B. (1984). Measuring adjustment to college. Journal of Counseling Psychology, 31, 179-189

6. Barefoot, B. O., Warnock, C., Dickinson, M., Richardson, S, \& Roberts, M. (Eds.). (1998). Exploring the evidence: Reporting outcomes of first-year seminars, Vol. II (Monograph No. 25). Columbia, SC: University of South Carolina, National Resource Center for The First-Year Experience and Students in Transition.

7. Bell, B. J. (in press). Assessing the effectiveness of an adventure-based first-year experience class. Journal of College Student Development

8. Bell, B. J. (2006). Wilderness orientation: Exploring the relationship between college preorie ntation programs and social support. Journal of Experiential Education, 29, 145-167.

9. Bell, B. J. (2008). The Neighborhood Project: A National Census of Outdoor Orientation Progr ams at FourYear Colleges in the United States. Martinsville, IN: Coalition for Education i $\mathrm{n}$ the Outdoors Ninth Biennial Research Symposium Abstracts.

10. Bell, B. J., \& Holmes, M. R. (2011). Important factors leading to outdoor orientation program outcomes: A qualitative exploration of survey results. Journal of Outdoor Recreation, Education and Leadership, 3(1), 26-39. 
11. Bell, B. J., Holmes, M. R., Vigneault, B., \& Williams, B. (2007). Student Involvement: Critical concerns of outdoor orientation programs. Journal of Experiential Education, 30(3), 253257.

12. Berman, J. \& Berman, D. (1996).Using the wilderness to facilitate adjustment to college: An update description of wilderness orientation programs. The Journal of Experiential Educ ation, 19, 22-28.

13. Brody, N. (2004). What cognitive intelligence is and what emotional intelligence is not. Psychological Inquiry, 15, 234-238.

14. Bobilya, A.J., Akey, L., \& Mitchell Jr., D. (2009). Outcomes of a Spiritually Focused Wilderness Orientation Program. Journal of Experiential Education, 31(3), Retrieved from ERIC database

15. Chickering, A. W., Dalton, J. C., \& Stamm, L. (2006). Encouraging authenticity and spirituality in higher education. San Francisco: Jossey-Bass.

16. Ciarrochi, J., Chan, A.Y. \& Bajgar, J. (2001). Measuring emotional intelligence in adolescents. Personality and Individual Differences. 31, 1105-1119.

17. Ciarrochi, J., Chan, A., \& Caputi, P. (2000). A critical evaluation of the emotional intelligence construct. Personality and Individual Differences, 28, 539-561

18. Ciarrochi, J., Deane, F., \& Anderson, S. (2002). Emotional intelligence moderates the relationship between stress and mental health. Personality and Individual Differences, 32, 197-209.

19. Cooper, A. \& Petrides, K. V. (2010). A psychometric analysis of the Trait Emotional Intelligence Questionnaire-Short Form (TEIQue-SF) using Item Response Theory. Journal of Personality Assessment, 92, 449-457

20. Driver, B.L. (1983). Master list of items for Recreation Experience Preference scales and domains. Unpublished document. USDA Forest Service, Fort Collins, CO: Rocky Mountain Forest and Range Experiment Station

21. Ewert, A. (1977). The effects of outdoor adventure activities upon self-concept. Unpublished manuscript, Eastern Washington, Cheney, Washington, State 
22. Frauman, E. \& Waryold, D. (2009). An exploratory study of the impact of a wilderness orientation program on college student's life effectiveness. Journal or Outdoor Recreation, Education and Leadership, 1(2)

23. Freudenthaler, H. H., Neubauer, A. C., Gabler, P., \& Scherl, W. G. (2008). Testing the Trait Emotional Intelligence Questionnaire (TEIQue) in a German-speaking sample. Personality and Individual Differences, 45, 673-678

24. Fox, L., Zakely, J., Morris. R. \& Jundt. M. (1993). Orientation as a catalyst: Effective retention through academic and social integration, In M. L. Upcraft, R. H. Mullendore. B. O. Barefoot. \&D. S. Fidler (Eds.), Designing successful transitions: A guide for orienting students to college (pp. 49-59). Columbia, SC: National Resource Center for the Freshman Year Experience.

25. Gardner, H. (1983). Fames of mind: The theory of multiple intelligences. New York: Basic Books.

26. Gardner, J., \& Hansen, D. (1993). Perspectives on the future of orientation. In M.L. Upcrapft, R. H. Mulldore, B. O. Barefoot, \& D. S. Fidler (Eds.), Designing successful transitions: A guide for orienting students to college. Columbia, SC: The University of South Carolina, 72-83.

27. Garst, B., Scheider, I., \& Baker, D. (2001). Outdoor Adventure Program Participation Impacts on Adolescent Self-Perception. Journal of Experiential Education, 24(1), 41. Retrieved from EBSCOhost.

28. Gass, M. A. (1986). The effects of a wilderness orientation program on incoming students to a university setting. Unpublished Dissertation, University of Colorado, Boulder.

29. Gass, M. A., Garvey, D. E. \& Sugerman, D. A. (2003). The long term effects of a firstyear student wilderness orientation program. Journal of Experiential Education, 26, 3440.

30. Goleman, D. (1995). Emotional intelligence: Why it can matter more than IQ. New York: Bantam Books. 
31. Goleman, D. (1998). Working with Emotional Intelligence, Bloomsburg Publishing, London

32. Griffin, J. (2003). The Effects of an Adventure Based Program with an Explicit Spiritual Component on the Spiritual Growth of Adolescents. Journal of Experiential Education, 25(3), 351. Retrieved from EBSCOhost.

33. Grout, S. J. (2009). The Influence of a Challenge Course Based Pre-Orientation's Curriculum Integration on Participants' Perceived Self Efficacy. Unpublished Dissertation, West Virginia University, Morgantown

34. Hattie, J., Marsh, H. W., Neil, J.T. \& Richards, G.E. (1997). Adventure education and Outward Bound: Out of class experiences that make a lasting difference. Review of Educational Research, 67, 43-87.

35. Hausmann, L. R., Schofield, J. W., \& Woods, R. (2007). Sense of Belonging as a Predicator of Intentions to Persist among African American and White First-Year College Students. Research in Higher Education, 48(7), Retrieved from ERIC database doi: 10.1007/s11162007-9052-9

36. History of the First Year Seminar \& University 101 Program. (n.d.). Retrieved March 30, 2010 from http://www.sc.edu/univ101/aboutus/history.html

37. Hooke, D. O. (1987). Reaching that Peak: 75 years of the Dartmouth Outing Club. Canaan, NH: Phoenix

38. Jaeger, A.J., \& Eagan, M.K. (2007). Exploring the Value of Emotional Intelligence: A Means to Improve Academic Performance. NASPA Journal, 44(3), Retrieved from ERIC database

39. Jamelske, E. (2008). Measuring the Impact of a University first-Year-Experience Program on Student GPA and Retention. Research in Higher Education, 57. Retrieved from ERIC database doi: 10.1007/s11162-007-9052-9

40. John, O. P., Naumann, L. P., \& Soto, C. J. (2008). Paradigm Shift to the Integrative Big-Five Trait Taxonomy: History, Measurement, and Conceptual Issues. In O. P. John, R. W. Robins, \& L. A. Pervin (Eds.), Handbook of personality: Theory and research (pp. 114158). New York, NY: Guilford Press 
41. Jones, J. J., \& Hinton, J. L. (2007). Study of self-efficacy in a freshman wilderness experience program: Measuring general versus specific gains. Journal of Experiential Education, 29, 382-385. Retrieved from ERIC database.

42. Kolb, D. A. (1984). Experiential learning: Experience as the source of learning and developme $n t$. New Jersey: Prentice-Hall.

43. Lane, W. C., \& Ellis, R. A., (1968). Social Mobility and Anticipatory Socialization. The Pacific Sociological Review, 11(1), 5-14, Retrieved from http://www.jstor.org/stable/pdfplus/1388519.pdf?acceptTC=true

44. LaPlante. A. (1991). How IS execs can fill business-skills gaps. Computer-world. 2S, 90-97

45. Liptak, J.J. (2005). Using Emotional intelligence to help college students succeed in the workplace. Journal of Employment Counseling, 42, 171-178.

46. Mavroveli, S., Petrides, K. V., Sangareau, Y., \& Furnham, A. (2009). Exploring the relationships between trait emotional intelligence and objective socio-emotional outcomes in childhood. British Journal of Educational Psychology, 79, 259-272.

47. Mayer. J. D., Salovey. P. \& Caruso. D, (2000), Models of Emotional Intelligence. In R. J, Sternberg (Ed,). Handbook of intelligence (pp, .396-420), Cambridge. England: Cambridge University Press.

48. Merton, R. (1957). Social Theory and Social Structure. Glencoe, IL: The Free Press.

49. Mikolajczak, M., Luminet, O., Leroy, C., \& Roy, E. (2007). Psychometric Properties of the Trait Emotional Intelligence Questionnaire: Factor Structure, Reliability, Construct, and Incremental Validity in a French-Speaking Population. Journal of Personality Assessment, 88, 338-353.

50. Mikolajczak, M., Menil, C., \& Luminet, O. (2007). Explaining the protective effect of trait emotional intelligence regarding occupational stress: exploration of emotional labour processes. Journal of Research in Personality, 41, 1107-1117. 
51. Mikolajczak, M., Petrides, K. V., Luminet, O., \& Coumans, N. (2009). An experimental investigation of the moderating effects of trait emotional intelligence on laboratoryinduced stress. International Journal of Clinical and Health Psychology, 9, 455-477.

52. Morris, J. A., Urbanski, J.,\& Fuller, J. (2005). Using poetry and visual arts to develop emotional intelligence. Journal of Management Education, 29, 888-905.

53. Neill, J. (2008) Enhancing life effectiveness: The impacts of outdoor education programs, PhD Thesis, University of Western Sydney

54. Parker, J.D., Hogan, M.J., Eastabrook, J.M., Oke, A. \& Wood, L.M. (2006). Emotional intelligence and student retention: Predicting the successful transition from high school to university. Personality and Individual Differences, 41(7), 1329-1336.

55. Parker, J. D. A., Saklofske, D. H., Wood, L. M., \& Collin, T. (2009). The role of emotional intelligence in education. In C. Stough, D. H. Saklofske, \& J. D. A. Parker (Eds.), Assessing Emotional Intelligence: Theory, Research and Applications. New York: Springer.

56. Parker, J. D., Saklofske, D. H., Wood, L. M., Eastabrook, J. M., \& Taylor, R. N. (2005). Stability and change in emotional intelligence: Exploring the transition to young adulthood. Journal of Individual Differences, 26, 100-106.

57. Parker, J.D., Summerfeldt, L.J., Hogan, M.J., \& Majeski, S.A. (2004). Emotional intelligence and Academic Success: Examining the Transition from High School to University. Personality and Individual Differences, 36. Retrieved from ERIC database

58. Pascarella, E. T., \& Terenzini, P.T. (1991). How College affects students. San Francisco: Jossey-Bass Publishers.

59. Pascarella, E.T., \& Terenzini, P.T. (2005) How college affects students: $A$ third decade of research (Vol. 2). San Francisco, CA: Jossey-Boss

60. Pascarella, E., Terenzini, P., \& Wolfe, L. (1986). Orientation to college and freshman year persistence / withdrawal decisions. Journal of Higher Education, 57, 155 - 175. 
61. Paxton, T., \& McAvoy, L. (2000). Social psychological benefits of a wilderness adventure program. In: McCool, Stephen F.; Cole, David N.; Borrie, William T.; O'Loughlin, Jennifer, comps. 2000. Wilderness science in a time of change conference-Volume 3: Wilderness as a place for scientific inquiry; 1999 May 23-27; Missoula, MT. Proceedings RMRS-P-15VOL-3. Ogden, UT: U.S. Department of Agriculture, Forest Service, Rocky Mountain Research Station. 275

62. Petrides, K.V., Frederickson, N., \& Furnham, A. (2004). The role of trait emotional intelligence in academic performance and deviant behavior at school. Personality and Individual Differences, 36, 277-293.

63. Petrides, K. V. \& Furnham, A. (2000). On the dimensional structure of emotional intelligence. Personality and Individual Differences, 29, 313-320.

64. Petrides, K. V. \& Furnham, A. (2001). Trait emotional intelligence: Psychometric investigation with reference to established trait taxonomies. European Journal Personality, 15, 425-448.

65. Petrides, K. V. \& Furnham, A. (2003). Trait emotional intelligence: Behavioural validation in two studies of emotion recognition and reactivity to mood induction. European Journal of Personality, 17, 39-57

66. Petrides, K.V., \& Furnham, A. (2006). The role of trait emotional intelligence in a genderspecific model of organizational variables. Journal of Applied Social Psychology, 36(2), 552-569.

67. Petrides, K. V., Furnham, A., \& Mavroveli, S. (2007). Trait emotional intelligence: Moving forward in the field of El. In G. Matthews, M. Zeidner, \& R. Roberts (Eds.), Emotional intelligence: Knowns and unknowns - Series in affective science (pp. 151-166). Oxford: Oxford University Press.

68. Petrides, K. V., Pérez-González, J. C., \& Furnham, A. (2007). On the criterion and incremental validity of trait emotional intelligence. Cognition and Emotion, 21, 26-55

69. Petrides, K. V., Pita, R., \& Kokkinaki, F. (2007). The location of trait emotional intelligence in personality factor space. British Journal of Psychology, 98, 273-289 
70. Petrides, K. V., Sangareau, Y., \& Furnham, A., \& Frederickson, N. (2006). Trait emotional intelligence and children's peer relations at school. School Development, 15, 537-547

71. Porter, O. F. (1990). Undergraduate completion and persistence at four-year colleges and universities: Detailed Findings. Washington, DC: National Institute of Independent Colleges and Universities

72. Porter, S. R., \& Swing, R. L. (2006). Understanding how first-year seminars affect persistence. Research in High Education, 47, 89-109

73. Propst, D.B, \& Koesler, R. A. (1998). Bandura goes outdoors: Role of self-efficacy in the outdoor leadership development process. Leisure Sciences, 20, 319-344.

74. Qualter, P., Gardner, K., Whiteley, H., Dudiak, H. \& Pope., D. (n.d.). The role of emotional intelligence in high education. Retrieved May 05, 2011, from http://www.psychology.heacademy.ac.uk/docs/doc/HEA_special_report.doc

75. Qualter, P., Whiteley, H. E., Hutchinson, J. M., \& Pope, D. J. (2007). Supporting the Development of Emotional Intelligence Competencies to Ease the Transition from Primary to High School. Educational Psychology in Practice, 23(1), 79-95. doi:10.1080/02667360601154584

76. Qualter, P. Whiteley, H.E., Morley, A.M., \& Dudiak, H. (2009) The role of Emotional Intelligence in the decision to persist with academic studies in HE. Post Compulsory Education, 14, 219-231.

77. Richardson, E. D. (2003). Adventure-based therapy and self-efficacy theory: Test of a treatment model for late adolescents with depressive symptomatology. Dissertation Abstracts International, 63(9-B), 4384. (UMI No. AA13065456)

78. Robison, D., Burns, C., \& Gaw, K., (1996). Orientation Programs: A Foundation for Student Learning and Success.

79. Salovey, P., \& Mayer, J. D. (1990). Emotional intelligence. Imagination, Cognition and Personality, 9 (3), 185-211. 
80. Sanchez, R. J., Bauer, T. N., \& Paronto, M. E. (2006). Peer-Mentoring Freshmen: Implications for Satisfaction, Commitment, and Retention to Graduation. Academy of Management Learning \& Education, 5(1), 25-37. doi:10.5465/AMLE.2006.20388382

81. Sax, L. J., Astin, A. W., Korn, W. S., \& Mahoney, M. K. 1995. The American College Freshmen: National Norms for Fall 1995. Los Angeles: Higher Education Research Institute, University of California, Los Angeles

82. Shivpuri, S., \& Kim, B. (2004). Do employers and colleges see eye-lo-eye? College student development and assessment. NACE Journal, 65, 37-44.

83. Smith, C. A., Strand, S. E., \& Bunting, C. J. (2002). The Influence of Challenge Course Participation on Moral and Ethical Reasoning. Journal of Experiential Education, 25(2), 278. Retrieved from EBSCOhost.

84. Tinto, V. (1987). Rethinking the causes and curses of student attrition. Chicago: University of Chicago Press

85. Thorndike, R. L. (1920). Intelligence and its use. Harper's Magazine, 140, 227-235.

86. Vandervoort, D. J. (2006). The Importance of Emotional Intelligence in Higher Education. Current Psychology, 25(1), 3-7. Retrieved from EBSCOhost

87. Wilcox, P., Winn, S., \& Fyvie-Gauld, M. (2005). 'It was nothing to do with the university, it was just the people': The role of social support in the first-year experience of higher education. Studies in Higher Education, 30(6), 707-722. doi:10.1080/03075070500340036

88. Zee, K.V., Thijs, M., \& Schakel, L. (2002). The Relationship of emotional intelligence with academic intelligence and the big five. European Journal of Personality, 16. Retrieved from ERIC database, doi: 10.1002/per.434 


\section{Appendices}

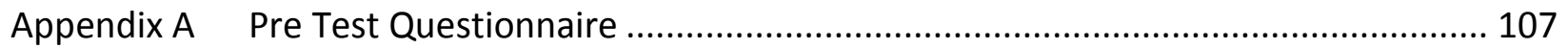

Appendix B Post Test Questionnaire ................................................................... 114 
Adventure West Virginia Program Evaluation

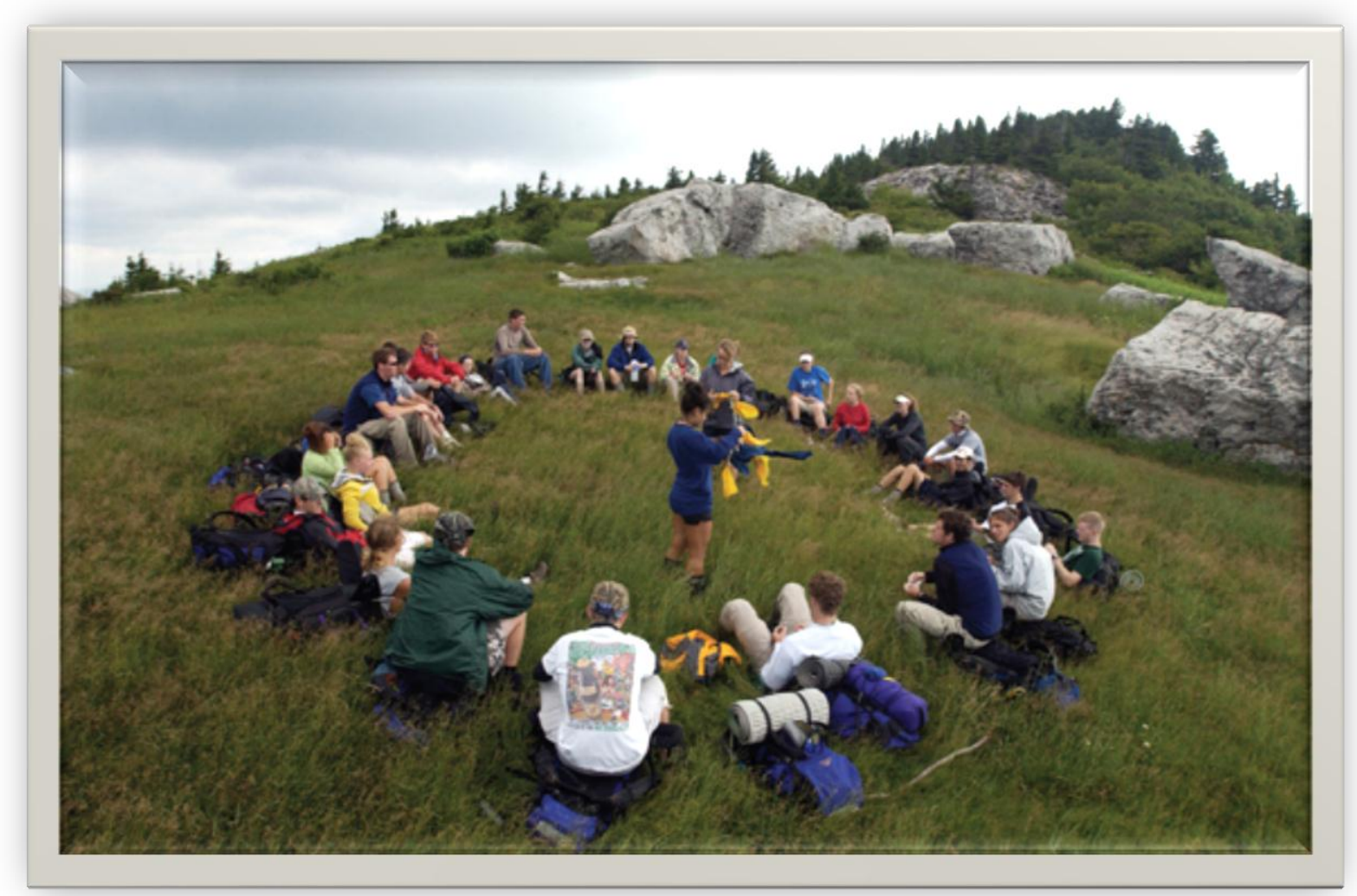

Pre-Program Evaluation

Trip ID-

Survey \#- 
Dear Adventure West Virginia Participant,

Thank you for agreeing to participate in this study. The purpose of this study is to evaluate the experiences and beneficial outcomes you attained during the Adventure West Virginia Program. This is an opportunity for you to help improve future Adventure West Virginia programs. Your responses are critical to the success of this outdoor orientation program and this research project.

It should take you about 10 minutes to complete the survey. You do not have to answer every question. Your answers are strictly confidential and your name will in no way be connected with the results. This study is being conducted by West Virginia University and will help meet the requirements for a master's thesis. This is a research project.

Please return it to the researcher when you have completed the survey. We are grateful for the help you have given us. If you have any questions, please feel free to contact me.

Sincerely,

Coy Belknap, B.S.

Dr. Chad Pierskalla

cbelknap@mix.wvu.edu

cpierska@wvu.edu 
Trip ID-

Survey \#-

\section{Reasons for Choosing WVU}

1. What were the three most important reasons for choosing WVU? Check only 3.

Most Important

a. Academics

b. Cost of education

c. Family

d. Friends came here

e. Major/field of study

f. Location

g. Financial aid
h. Social life
i. Athletics
j. Other (Specify Below)
○

Second

Third

0

O

O

○

○

○

○

○

○

O 


\section{Reasons for Participating in Adventure West Virginia}

2. Students have many reasons why they might enjoy and benefit from participating in Adventure West Virginia. How important are each of the following experiences as reasons for choosing this program? Circle one response for each motivation item listed.

\begin{tabular}{|c|c|c|c|c|c|c|c|}
\hline Experiences & $\begin{array}{c}\text { Not } \\
\text { Important }\end{array}$ & $\begin{array}{c}\text { Low } \\
\text { Importance }\end{array}$ & $\begin{array}{l}\text { Slightly } \\
\text { Important }\end{array}$ & Neutral & $\begin{array}{l}\text { Moderately } \\
\text { Important }\end{array}$ & $\begin{array}{c}\text { Very } \\
\text { Important }\end{array}$ & $\begin{array}{l}\text { Extremely } \\
\text { Important }\end{array}$ \\
\hline To gain a sense of self confidence & 1 & 2 & 3 & 4 & 5 & 6 & 7 \\
\hline To feel independence & 1 & 2 & 3 & 4 & 5 & 6 & 7 \\
\hline To take risks & 1 & 2 & 3 & 4 & 5 & 6 & 7 \\
\hline To be with members of your group (friends) & 1 & 2 & 3 & 4 & 5 & 6 & 7 \\
\hline To talk to new and varied people & 1 & 2 & 3 & 4 & 5 & 6 & 7 \\
\hline $\begin{array}{l}\text { To develop your knowledge of things here (WVU, } \\
\text { Morgantown, WV) }\end{array}$ & 1 & 2 & 3 & 4 & 5 & 6 & 7 \\
\hline To view the scenery & 1 & 2 & 3 & 4 & 5 & 6 & 7 \\
\hline To develop personal, spiritual values & 1 & 2 & 3 & 4 & 5 & 6 & 7 \\
\hline To help get rid of some clutched-up feelings & 1 & 2 & 3 & 4 & 5 & 6 & 7 \\
\hline To experience tranquility & 1 & 2 & 3 & 4 & 5 & 6 & 7 \\
\hline To be near considerate people & 1 & 2 & 3 & 4 & 5 & 6 & 7 \\
\hline To teach your outdoor skills to others & 1 & 2 & 3 & 4 & 5 & 6 & 7 \\
\hline To be near others who could help if you need them & 1 & 2 & 3 & 4 & 5 & 6 & 7 \\
\hline To have others think highly of you for participating & 1 & 2 & 3 & 4 & 5 & 6 & 7 \\
\hline To be my own boss & 1 & 2 & 3 & 4 & 5 & 6 & 7 \\
\hline To chance dangerous situations & 1 & 2 & 3 & 4 & 5 & 6 & 7 \\
\hline $\begin{array}{l}\text { To be with people who enjoy the same things } \\
\text { you do }\end{array}$ & 1 & 2 & 3 & 4 & 5 & 6 & 7 \\
\hline To be with and observe other people using the area & 1 & 2 & 3 & 4 & 5 & 6 & 7 \\
\hline To experience new and different things & 1 & 2 & 3 & 4 & 5 & 6 & 7 \\
\hline To be close to nature & 1 & 2 & 3 & 4 & 5 & 6 & 7 \\
\hline To think about your personal values & 1 & 2 & 3 & 4 & 5 & 6 & 7 \\
\hline To have your mind move at a slower pace & 1 & 2 & 3 & 4 & 5 & 6 & 7 \\
\hline To feel isolated & 1 & 2 & 3 & 4 & 5 & 6 & 7 \\
\hline To be with respectful people & 1 & 2 & 3 & 4 & 5 & 6 & 7 \\
\hline To help direct the activities of others & 1 & 2 & 3 & 4 & 5 & 6 & 7 \\
\hline To become better at a particular skill & 1 & 2 & 3 & 4 & 5 & 6 & 7 \\
\hline To control things & 1 & 2 & 3 & 4 & 5 & 6 & 7 \\
\hline To get to know the lay of the land & 1 & 2 & 3 & 4 & 5 & 6 & 7 \\
\hline To get away from the usually demands of life & 1 & 2 & 3 & 4 & 5 & 6 & 7 \\
\hline To be away from crowds of people & 1 & 2 & 3 & 4 & 5 & 6 & 7 \\
\hline To test your abilities & 1 & 2 & 3 & 4 & 5 & 6 & 7 \\
\hline To study nature & 1 & 2 & 3 & 4 & 5 & 6 & 7 \\
\hline To have a change from your daily routine & 1 & 2 & 3 & 4 & 5 & 6 & 7 \\
\hline To get away from the clatter and racket back home & 1 & 2 & 3 & 4 & 5 & 6 & 7 \\
\hline To have thrills & 1 & 2 & 3 & 4 & 5 & 6 & 7 \\
\hline To test your endurance & 1 & 2 & 3 & 4 & 5 & 6 & 7 \\
\hline To tell others about the trip & 1 & 2 & 3 & 4 & 5 & 6 & 7 \\
\hline
\end{tabular}




\section{About You}

This set of questions will help us better understand you and compare your answers to those of other students. You answers will not be used for anything other than to create general categories for students participating in Adventure West Virginia.

3. Instructions: Please answer each statement below by putting a circle around the number that best reflects your degree of agreement or disagreement with that statement. Do not think too long about the exact meaning of the statements. Work quickly and try to answer as accurately as possible. There are no right or wrong answers. There are seven possible responses to each statement ranging from 'Completely Disagree' (number 1) to 'Completely Agree' (number 7).

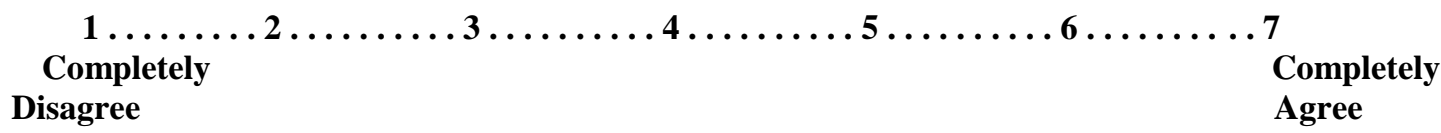

\begin{tabular}{|c|c|c|c|c|c|c|c|}
\hline Expressing my emotions with words is not a problem for me. & 1 & 2 & 3 & 4 & 5 & 6 & 7 \\
\hline I often find it difficult to see things from another person's viewpoint. & 1 & 2 & 3 & 4 & 5 & 6 & 7 \\
\hline On the whole, I'm a highly motivated person. & 1 & 2 & 3 & 4 & 5 & 6 & 7 \\
\hline I usually find it difficult to regulate my emotions. & 1 & 2 & 3 & 4 & 5 & 6 & 7 \\
\hline I generally don't find life enjoyable. & 1 & 2 & 3 & 4 & 5 & 6 & 7 \\
\hline I can deal effectively with people. & 1 & 2 & 3 & 4 & 5 & 6 & 7 \\
\hline I tend to change my mind frequently. & 1 & 2 & 3 & 4 & 5 & 6 & 7 \\
\hline Many times, I can't figure out what emotion I'm feeling. & 1 & 2 & 3 & 4 & 5 & 6 & 7 \\
\hline I feel that I have a number of good qualities. & 1 & 2 & 3 & 4 & 5 & 6 & 7 \\
\hline I often find it difficult to stand up for my rights. & 1 & 2 & 3 & 4 & 5 & 6 & 7 \\
\hline I'm usually able to influence the way other people feel. & 1 & 2 & 3 & 4 & 5 & 6 & 7 \\
\hline On the whole, I have a gloomy perspective on most things. & 1 & 2 & 3 & 4 & 5 & 6 & 7 \\
\hline Those close to me often complain that I don't treat them right. & 1 & 2 & 3 & 4 & 5 & 6 & 7 \\
\hline I often find it difficult to adjust my life according to the circumstances. & 1 & 2 & 3 & 4 & 5 & 6 & 7 \\
\hline On the whole, I'm able to deal with stress. & 1 & 2 & 3 & 4 & 5 & 6 & 7 \\
\hline I often find it difficult to show my affection to those close to me. & 1 & 2 & 3 & 4 & 5 & 6 & 7 \\
\hline I'm normally able to "get into someone's shoes" and experience their emotions. & 1 & 2 & 3 & 4 & 5 & 6 & 7 \\
\hline I normally find it difficult to keep myself motivated. & 1 & 2 & 3 & 4 & 5 & 6 & 7 \\
\hline I'm usually able to find ways to control my emotions when I want to. & 1 & 2 & 3 & 4 & 5 & 6 & 7 \\
\hline
\end{tabular}


1 .

Completely

Disagree $\ldots 7$

Completely

Agree

\begin{tabular}{|l|c|c|c|c|c|c|c|}
\hline On the whole, I'm pleased with my life. & 1 & 2 & 3 & 4 & 5 & 6 & 7 \\
\hline I would describe myself as a good negotiator. & 1 & 2 & 3 & 4 & 5 & 6 & 7 \\
\hline I tend to get involved in things I later wish I could get out of. & 1 & 2 & 3 & 4 & 5 & 6 & 7 \\
\hline I often pause and think about my feelings. & 1 & 2 & 3 & 4 & 5 & 6 & 7 \\
\hline I believe I'm full of personal strengths. & 1 & 2 & 3 & 4 & 5 & 6 & 7 \\
\hline I tend to "back down" even if I know I'm right. & 1 & 2 & 3 & 4 & 5 & 6 & 7 \\
\hline I don't seem to have any power at all over other people's feelings. & 1 & 2 & 3 & 4 & 5 & 6 & 7 \\
\hline I generally believe that things will work out fine in my life. & 1 & 2 & 3 & 4 & 5 & 6 & 7 \\
\hline I find it difficult to bond well even with those close to me. & 1 & 2 & 3 & 4 & 5 & 6 & 7 \\
\hline Generally, I'm able to adapt to new environments. & 1 & 2 & 3 & 4 & 5 & 6 & 7 \\
\hline Others admire me for being relaxed. & 1 & 2 & 3 & 4 & 5 & 6 & 7 \\
\hline
\end{tabular}

3. What is your gender?
a. Male
b. Female

4. Are you?
a. Hispanic or Latino(a)
b. Not Hispanic or Latino(a)

5. What is your ethnicity?
a. American Indian / Alaskan Native
b. Asian
c. Black / African American
d. Native Hawaiian or other Pacific Islander
e. White
f. Other -

6. What is your current residency?
a. West Virginia
b. Other State
c. International

7. Did either of your parents graduate from college?
a. Yes (go to Question 8)
b. No (go to Question 9)

8. If yes to question 6, did either of your parents attend West Virginia University?
a. Yes
b. No

9. What was your cumulative GPA at the end of high school? 
10. What is your planned major?

11. While in high school, did you participate in any class-related service learning activities?
a. Yes
b. No

12. While in high school, did you participate in extracurricular activities (i.e. athletics, student council/government, marching band, co-op, FFA, FBLA, etc.)?
a. Yes
b. No

Please return the survey to the researcher before you leave. Thank You!

\author{
Coy Belknap \\ 322 Percival Hall \\ Evansdale Drive \\ P.O. Box 6125 \\ Morgantown WV, 26506
}


Adventure West Virginia Program Evaluation

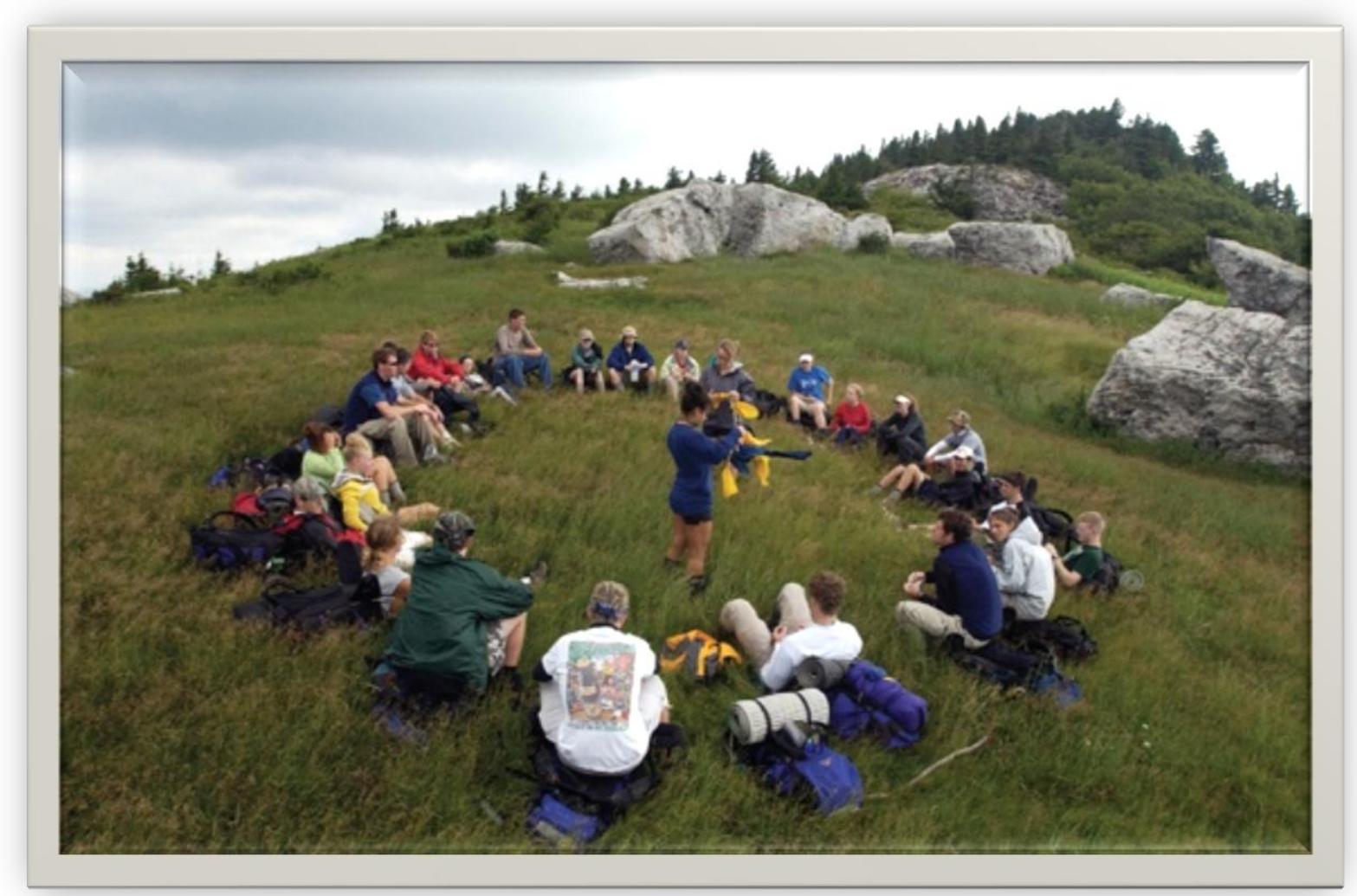

Post Program Evaluation

Trip ID-

Survey \#- 
Dear Adventure West Virginia Participant,

Thank you for agreeing to participate in this study. The purpose of this study is to evaluate the experiences and outcomes you attained during the Adventure West Virginia Program. This is an opportunity for you to help improve future Adventure West Virginia programs. Your responses are critical to the success of this outdoor orientation program and this project.

It should take you about 10 minutes to complete the survey. You do not have to answer every question. Your answers are strictly confidential and your name will in no way be connected with the results. This study is being conducted by West Virginia University and will help meet the requirements for a master's thesis. This is a research project.

Please return it to the researcher when you have completed the survey. We are grateful for the help you have given us. If you have any questions, please feel free to contact me.

Sincerely,

Coy Belknap, B.S.

Dr. Chad

Pierskalla

cbelknap@mix.wvu.edu

cpierska@wvu.edu 
Trip ID-

\section{Attainment of Experiences}

Survey-

1. To what extant were you able to attain or realize each of the following experiences during the Adventure West Virginia program? Circle one for each.

\begin{tabular}{|c|c|c|c|c|}
\hline & $\begin{array}{l}\text { Not at all } \\
\text { Able }\end{array}$ & $\begin{array}{l}\text { Somewhat } \\
\text { Able }\end{array}$ & $\begin{array}{l}\text { Moderately } \\
\text { Able }\end{array}$ & Totally Able \\
\hline To gain a sense of self confidence & 1 & 2 & 3 & 4 \\
\hline To feel independence & 1 & 2 & 3 & 4 \\
\hline To take risks & 1 & 2 & 3 & 4 \\
\hline To be with members of your group (friends) & 1 & 2 & 3 & 4 \\
\hline To talk to new and varied people & 1 & 2 & 3 & 4 \\
\hline To develop your knowledge of things here (WVU, Morgantown, WV) & 1 & 2 & 3 & 4 \\
\hline To view the scenery & 1 & 2 & 3 & 4 \\
\hline To develop personal, spiritual values & 1 & 2 & 3 & 4 \\
\hline To help get rid of some clutched-up feelings & 1 & 2 & 3 & 4 \\
\hline To experience tranquility & 1 & 2 & 3 & 4 \\
\hline To be near considerate people & 1 & 2 & 3 & 4 \\
\hline To teach your outdoor skills to others & 1 & 2 & 3 & 4 \\
\hline To be near others who could help if you need them & 1 & 2 & 3 & 4 \\
\hline To have others think highly of you for participating & 1 & 2 & 3 & 4 \\
\hline To be my own boss & 1 & 2 & 3 & 4 \\
\hline To chance dangerous situations & 1 & 2 & 3 & 4 \\
\hline To be with people who enjoy the same things you do & 1 & 2 & 3 & 4 \\
\hline To be with and observe other people using the area & 1 & 2 & 3 & 4 \\
\hline To experience new and different things & 1 & 2 & 3 & 4 \\
\hline To be close to nature & 1 & 2 & 3 & 4 \\
\hline To think about your personal values & 1 & 2 & 3 & 4 \\
\hline To have your mind move at a slower pace & 1 & 2 & 3 & 4 \\
\hline To feel isolated & 1 & 2 & 3 & 4 \\
\hline To be with respectful people & 1 & 2 & 3 & 4 \\
\hline To help direct the activities of others & 1 & 2 & 3 & 4 \\
\hline To become better at a particular skill & 1 & 2 & 3 & 4 \\
\hline To control things & 1 & 2 & 3 & 4 \\
\hline To get to know the lay of the land & 1 & 2 & 3 & 4 \\
\hline To get away from the usually demands of life & 1 & 2 & 3 & 4 \\
\hline To be away from crowds of people & 1 & 2 & 3 & 4 \\
\hline To test your abilities & 1 & 2 & 3 & 4 \\
\hline To study nature & 1 & 2 & 3 & 4 \\
\hline To have a change from your daily routine & 1 & 2 & 3 & 4 \\
\hline To get away from the clatter and racket back home & 1 & 2 & 3 & 4 \\
\hline To have thrills & 1 & 2 & 3 & 4 \\
\hline To test your endurance & 1 & 2 & 3 & 4 \\
\hline To tell others about the trip & 1 & 2 & 3 & 4 \\
\hline
\end{tabular}


2. Instructions: Please answer each statement below by putting a circle around the number that best reflects your degree of agreement or disagreement with that statement. Do not think too long about the exact meaning of the statements. Work quickly and try to answer as accurately as possible. There are no right or wrong answers. There are seven possible responses to each statement ranging from 'Completely Disagree' (number 1) to 'Completely Agree' (number 7).

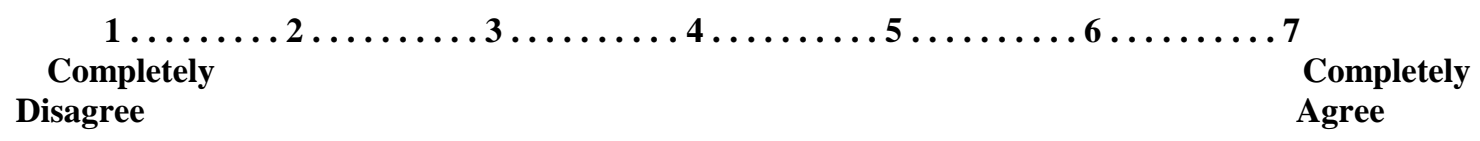

\begin{tabular}{|c|c|c|c|c|c|c|c|}
\hline Expressing my emotions with words is not a problem for me. & 1 & 2 & 3 & 4 & 5 & 6 & 7 \\
\hline I often find it difficult to see things from another person's viewpoint. & 1 & 2 & 3 & 4 & 5 & 6 & 7 \\
\hline On the whole, I'm a highly motivated person. & 1 & 2 & 3 & 4 & 5 & 6 & 7 \\
\hline I usually find it difficult to regulate my emotions. & 1 & 2 & 3 & 4 & 5 & 6 & 7 \\
\hline I generally don't find life enjoyable. & 1 & 2 & 3 & 4 & 5 & 6 & 7 \\
\hline I can deal effectively with people. & 1 & 2 & 3 & 4 & 5 & 6 & 7 \\
\hline I tend to change my mind frequently. & 1 & 2 & 3 & 4 & 5 & 6 & 7 \\
\hline Many times, I can't figure out what emotion I'm feeling. & 1 & 2 & 3 & 4 & 5 & 6 & 7 \\
\hline I feel that I have a number of good qualities. & 1 & 2 & 3 & 4 & 5 & 6 & 7 \\
\hline I often find it difficult to stand up for my rights. & 1 & 2 & 3 & 4 & 5 & 6 & 7 \\
\hline I'm usually able to influence the way other people feel. & 1 & 2 & 3 & 4 & 5 & 6 & 7 \\
\hline On the whole, I have a gloomy perspective on most things. & 1 & 2 & 3 & 4 & 5 & 6 & 7 \\
\hline Those close to me often complain that I don't treat them right. & 1 & 2 & 3 & 4 & 5 & 6 & 7 \\
\hline I often find it difficult to adjust my life according to the circumstances. & 1 & 2 & 3 & 4 & 5 & 6 & 7 \\
\hline On the whole, I'm able to deal with stress. & 1 & 2 & 3 & 4 & 5 & 6 & 7 \\
\hline I often find it difficult to show my affection to those close to me. & 1 & 2 & 3 & 4 & 5 & 6 & 7 \\
\hline I'm normally able to "get into someone's shoes" and experience their emotions. & 1 & 2 & 3 & 4 & 5 & 6 & 7 \\
\hline I normally find it difficult to keep myself motivated. & 1 & 2 & 3 & 4 & 5 & 6 & 7 \\
\hline I'm usually able to find ways to control my emotions when I want to. & 1 & 2 & 3 & 4 & 5 & 6 & 7 \\
\hline
\end{tabular}




\section{Question 2 Continued}

$1 \ldots \ldots \ldots 2 \ldots \ldots \ldots 3 \ldots \ldots \ldots 4 \ldots \ldots \ldots 5 \ldots \ldots \ldots 6 \ldots \ldots .6$

Completely

Completely

Disagree

Agree

\begin{tabular}{|l|c|c|c|c|c|c|c|}
\hline On the whole, I'm pleased with my life. & 1 & 2 & 3 & 4 & 5 & 6 & 7 \\
\hline I would describe myself as a good negotiator. & 1 & 2 & 3 & 4 & 5 & 6 & 7 \\
\hline I tend to get involved in things I later wish I could get out of. & 1 & 2 & 3 & 4 & 5 & 6 & 7 \\
\hline I often pause and think about my feelings. & 1 & 2 & 3 & 4 & 5 & 6 & 7 \\
\hline I believe I'm full of personal strengths. & 1 & 2 & 3 & 4 & 5 & 6 & 7 \\
\hline I tend to "back down" even if I know I'm right. & 1 & 2 & 3 & 4 & 5 & 6 & 7 \\
\hline I don't seem to have any power at all over other people's feelings. & 1 & 2 & 3 & 4 & 5 & 6 & 7 \\
\hline I generally believe that things will work out fine in my life. & 1 & 2 & 3 & 4 & 5 & 6 & 7 \\
\hline I find it difficult to bond well even with those close to me. & 1 & 2 & 3 & 4 & 5 & 6 & 7 \\
\hline Generally, I'm able to adapt to new environments. & 1 & 2 & 3 & 4 & 5 & 6 & 7 \\
\hline Others admire me for being relaxed. & 1 & 2 & 3 & 4 & 5 & 6 & 7 \\
\hline
\end{tabular}

\section{Overall Evaluation of Program}

3. How satisfied are you with the trip you just participated in? Circle One

Not at all Satisfied Slightly Satisfied $\quad$ Moderately $\quad$ Very Satisfied Extremely Satisfied 1

2

Satisfied

$\begin{array}{lll}3 & 4 & 5\end{array}$

4. What were the "high points" of the trip? What did you enjoy the most? If none, write none. 
5. Do you feel as if your trip has better prepared you for your transition into college?
a. Yes
b. No

Please return the survey to the researcher before you leave.

\title{
Thank You!
}

\author{
Coy Belknap \\ 322 Percival Hall \\ Evansdale Drive \\ P.O. Box 6125 \\ Morgantown WV, 26506
}

John H. 